\title{
Impacts of Vertical Structure of Convection in Global Warming: The Role of Shallow Convection $\mathscr{O}$
}

\author{
CHAO-AN CHEN \\ Research Center for Environmental Changes, Academia Sinica, Taipei, Taiwan \\ JIA-YUH YU \\ Department of Atmospheric Sciences, National Central University, Taoyuan City, Taiwan \\ CHIA CHOU \\ Research Center for Environmental Changes, Academia Sinica, and Department of Atmospheric \\ Sciences, National Taiwan University, Taipei, Taiwan
}

(Manuscript received 11 August 2015, in final form 18 March 2016)

\begin{abstract}
Global-warming-induced changes in regional tropical precipitation are usually associated with changes in the tropical circulation, which is a dynamic contribution. This study focuses on the mechanisms of the dynamic contribution that is related to the partition of shallow convection in tropical convection. To understand changes in tropical circulation and its associated mechanisms, 32 coupled global climate models from CMIP3 and CMIP5 were investigated. The study regions are convection zones with positive precipitation anomalies, where both enhanced and reduced ascending motions are found. Under global warming, an upward-shift structure of ascending motion is observed in the entire domain, implying a deepening of convection and a more stable atmosphere, which leads to a weakening of the tropical circulation. In a more detailed examination, areas with enhanced (weakened) ascending motion are associated with more (less) import of moist static energy by a climatologically bottom-heavy (top heavy) structure of vertical velocity, which is similar to a "rich get richer" mechanism. In a warmer climate, different climatological vertical profiles tend to induce different changes in atmospheric stability: the bottom-heavy (top heavy) structure brings a more (less) unstable condition and is favorable (unfavorable) to the strengthening of the convective circulation. The bottom-heavy structure is associated with shallow convection, while the top-heavy structure is usually related to deep convection. This study suggests a hypothesis and a possible linkage for projecting and understanding future circulation change from the current climate: shallow convection will tend to strengthen tropical circulation and enhance upward motion in a future warmer climate.
\end{abstract}

\section{Introduction}

Globally, an increase in mean precipitation (Allen and Ingram 2002; Held and Soden 2006; Meehl et al. 2007b; Trenberth et al. 2007; Collins et al. 2013) with a tendency of fewer light and more heavy rainfall events has been found in climate model simulations under global warming

Supplemental information related to this paper is available at the Journals Online website: http://dx.doi.org/10.1175/JCLI-D-15-0563.s1.

Corresponding author address: Chao-An Chen, Research Center for Environmental Changes, Academia Sinica, 128 Academia Road, Taipei 11529, Taiwan.

E-mail: joanne22@rcec.sinica.edu.tw
(Sun et al. 2007; O'Gorman and Schneider 2009; Liu et al. 2009; Allan et al. 2010; Chou et al. 2012). These trends have also been observed in historical records ( $\mathrm{Gu}$ et al. 2007; Wentz et al. 2007; Adler et al. 2008), even though the rates of change are slightly different, partially because of inconsistent periods between observations (Liepert and Previdi 2009). However, unlike temperature and moisture fields, precipitation changes in response to

Publisher's Note: This article was revised on 15 June 2016 to correct a typographical error in the Fig. 6 caption that appeared when originally published online.

Publisher's Note: This article was revised on 2 August 2016 to correct an editing error in the Fig. 5 caption. 
global warming tend to strongly vary in space (Meehl et al. 2007b). The agreement among climate model simulations on the spatial distribution of time-mean precipitation changes is very poor (Cubasch et al. 2001; Allen and Ingram 2002; Stott and Kettleborough 2002; Neelin et al. 2006; Meehl et al. 2007b). Significant variations in spatial and temporal changes exist on regional and seasonal scales, compared to the relatively uniform warming and moistening of the atmosphere. The different mean precipitation change in response to the warming shows that the climatologically wet area (season) becomes wetter and the dry area (season) becomes drier (Held and Soden 2006; Meehl et al. 2007b; Zhang et al. 2007; Allan and Soden 2007; Wentz et al. 2007; Liu and Allan 2012; Chou et al. 2007; Chou and Lan 2012). In addition, changes in precipitation frequency and intensity also show regional variations (Chen et al. 2012). Regions with increased mean precipitation are accompanied by an increased frequency of heavy rain events and increased rainfall intensity, even though there are fewer light rain events. On the other hand, regions with decreased mean precipitation have decreases in rainfall frequency and weakened rainfall intensity for most rain events, even though very heavy rain events are still intensified.

From a global point of view, the thermodynamic effect due to increased moisture is relatively uniform in space, which is recognized as the dominant contribution to the increase in mean precipitation. On the other hand, the dynamic component associated with changes in circulation usually varies with regions and offset each other between regions, thereby playing a secondary role (e.g., Emori and Brown 2005; Held and Soden 2006). Regionally, the dynamic contribution becomes much more important and is the main reason for the strong spatial variation of precipitation changes. Many studies have proposed mechanisms associated with the dynamic effects on regional mean precipitation changes (e.g., Chou and Neelin 2004; Kumar et al. 2004; Chou et al. 2009; Seager et al. 2010; Chadwick et al. 2013), as well as the variation of rainfall characteristics on a regional scale (Chen et al. 2012). The dynamic contribution can be mostly explained by changes in atmospheric vertical motion that is associated with the spatial variation of atmospheric circulation.

Although for global averages, a weakening of atmospheric circulation is found in all global warming simulations (Knutson and Manabe 1995; Held and Soden 2006; Vecchi and Soden 2007; Chadwick et al. 2013; Collins et al. 2013), changes in atmospheric circulation do not show consistent trends in observations (Vecchi et al. 2006; Sohn and Park 2010; Shi and Bates 2011; Tokinaga et al. 2012; Luo et al. 2012). Therefore, many studies using model simulations have made efforts to understand what mechanism may lead to circulation change. From the sensitivity study in Chou and Chen (2010), the higher (shallower) deep convection depth accompanies larger (smaller) gross moist stability, which indicates a more (less) stable atmosphere. The more stable (unstable) atmosphere leads to a weakening (strengthening) of the atmospheric circulation. Ma et al. (2012) proposed a mean advection of stratification change (MASC) mechanism to interpret changes in atmospheric circulation under global warming. With an increase in dry static stability, the MASC mechanism induces the cold (warm) advection in climatologically convective (subsidence) regions, which slows down the tropical circulation. Bony et al. (2013) suggested that the reduced radiative cooling associated with increased $\mathrm{CO}_{2}$ in the atmosphere provides a large contribution to the weakening of the tropical circulation in global warming simulations. From the perspective of boundary condition, the spatially uniform SST increase (SUSI) weakens both the Walker and Hadley circulations. On the other hand, the change in SST patterns leads to a change in low-level circulation and further affects the regional precipitation response to global warming. The change in SST patterns is an important factor to explain the warmer-get-wetter pattern and Hadley circulation change (Ma and Xie 2013). He et al. (2014) showed a consistent impact of SST pattern change on atmospheric circulation over equatorial oceans, especially over the equatorial Pacific. However, the change in SST pattern is not the deterministic factor in tropical circulation change. The effects of air-sea coupling and radiative forcing associated with increased $\mathrm{CO}_{2}$ also play important roles in the circulation change. Anderson et al. (2015) remind us that change in SST is a useful diagnostic index while it also plays a role associated with adjusting surface energy flux under global warming. From a global perspective, although the atmospheric circulation tends to become weakened in model simulations, which mechanism plays the dominant role is still an unsettled issue. For a regional scale, the circulation change shows a more complex spatial pattern, which may involve different mechanisms among regions.

For illustration, an example of the MPI-ESM-LR result is shown in Fig. 1. The boundary of the convergence zones is defined by $-\left\langle\bar{\omega} \partial_{p} \bar{q}\right\rangle=0$ (red dashed line), which is similar to that defined by $\omega_{500 \mathrm{ha}}=0$ (green short dashed line). The overbar denotes the climatology in the current climate, and the angle brackets represent the mass integration of quantities from 1000 to $100 \mathrm{hPa}$. Although the water vapor increases homogeneously under global warming (Fig. 1a), changes in precipitation show a strong spatial variation with coexistence of positive and negative anomalies within climatological convective zones (Fig. 1b). Interestingly, the vertical velocity over the midtroposphere illustrates opposite signs of changes with both strengthening (gray shaded) and weakening (orange shaded) of upward motion even within convective areas with positive rainfall anomalies 


\section{(a) $<q>^{\prime}: M P \mid-E S M-L R$}
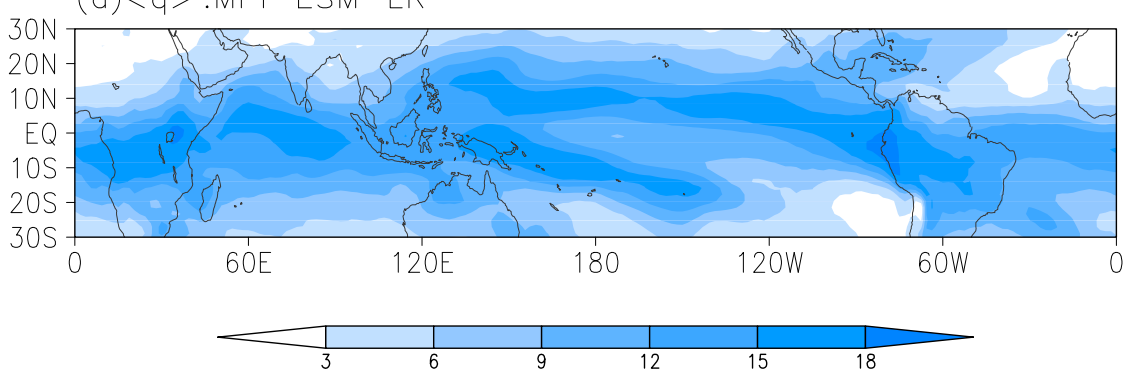

(b) $P^{\prime}$ and $\omega(500 h P a)$
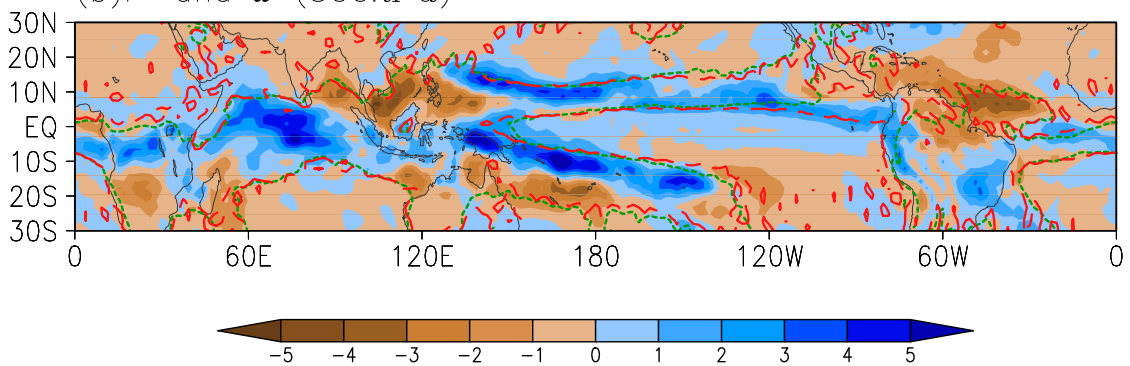

(c) $\omega^{\prime}(500 h P a)$ with $P^{\prime}>0$ within Con. area
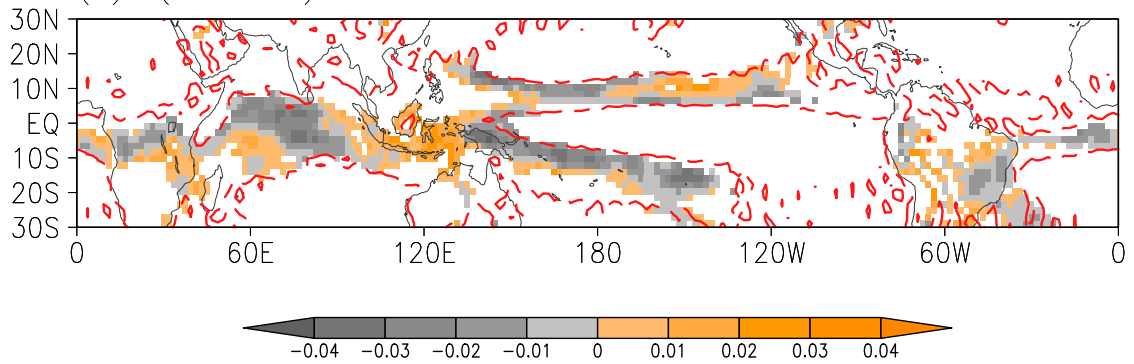

FIG. 1. Global-warming-induced changes in (a) column-integrated water vapor $(\mathrm{mm})$, (b) precipitation $\left(\mathrm{mm} \mathrm{day}^{-1}\right)$, and (c) vertical velocity $\left(\mathrm{Pa} \mathrm{s}^{-1}\right)$ at $500 \mathrm{hPa}$ over climatologically convective zones with positive precipitation anomalies. The results in December shown here are utilized as an example. These changes are from the MPI-ESM-LR model and were calculated by subtracting the 2080-99 climatology in the RCP8.5 scenario from the 1986-2005 climatology. The red squiggly-dashed lines in (b) and (c) represent the $-\left\langle\bar{\omega} \partial_{p} \bar{q}\right\rangle=0$ contour and the green short dashed lines in (b) represent the $\omega_{500 \mathrm{hPa}}=0$ contour, which denotes the boundary of convective regions during the 1986-2005 period.

(Fig. 1c). In other words, changes in precipitation are not always consistent with the changes in atmospheric vertical velocity. The latter exhibits a more complicated spatial distribution than the former. Although only showing a one month example pattern from one model, the anomalous strengthening and weakening of upward motion shown in Fig. 1c generally can be also found in other GCMs (see Figs. S1 and S2 in the supplemental material).

From a regional perspective, the circulation change shows a regional discrepancy, even within climatologically convective areas with increased rainfall (Fig. 1c). What mechanism leads the atmospheric circulation to have such diverse responses to a uniformly warm and humid climate is an interesting question and an unsettled issue. This opposite response to such a similar forcing environment motivates us to investigate the mechanisms related to regional change in atmospheric vertical motion under global warming. This study aims to answer the following two questions: (i) Does this change relate to regional atmospheric stability? (ii) What is the main factor that causes the changes in regional atmospheric stability? Understanding these questions may help us have a clearer picture of regional climate changes in the future.

Among possible mechanisms that have been proposed to account for changes in the tropical circulation, the role of shallow convection (denoting convection with a bottom-heavy structure of vertical velocity here) has seldom been discussed before, especially under global warming. Climatologically, shallow convection associated with shallow cumuli or congestus clouds provides 
TABLE 1. A list of 16 coupled atmosphere-ocean climate models in the CMIP3 archive used in this study. Expansions of acronyms are available online at http://www.ametsoc.org/PubsAcronymList.

\begin{tabular}{ll}
\hline \hline \multicolumn{1}{c}{ Model } & \multicolumn{1}{c}{ Description } \\
\hline CA_CCCma3.1_T47 & Canadian Centre for Climate Modelling and Analysis CGCM3.1 (spectral T47 resolution) (Canada) \\
CA_CCCma3.1_T63 & Canadian Centre for Climate Modelling and Analysis CGCM3.1 (spectral T63 resolution) (Canada) \\
CN_IAP & LASG, Institute of Atmospheric Physics, FGOALS-g1.0 (China) \\
FR_IPSL_CM4.1 & IPSL/Laboratoire de Météorologie Dynamique (LMD)/Laboratoire des Sciences du Climat et de \\
& l'Environment (LSCE), CM4 V1 (France) \\
GFDL_CCM2.0 & NOAA/Geophysical Fluid Dynamics Laboratory CM2.0 (United States) \\
GFDL_CCM2.1 & NOAA/Geophysical Fluid Dynamics Laboratory CM2.1 (United States) \\
GISS_AOM & NASA Goddard Institute for Space Studies, GISS-AOM (United States) \\
JP_CCSR3.2H & CCSR/National Institute for Environmental Studies (NIES)/FRCGC, MIROC3.2 (hires) (Japan) \\
JP_CCSR3.2M & CCSR/National Institute for Environmental Studies (NIES)/FRCGC, MIROC3.2 (medres) (Japan) \\
JP_MRI2.3 & Meteorological Research Institute (MRI) CGCM2.3.2a (Japan) \\
MPI_ECHAM5 & Max Planck Institute for Meteorology (MPI-M), ECHAM5/MPI-OM (Germany) \\
NCAR_CCSM3 & NCAR Community Climate System Model, version 3 (United States) \\
NCAR_PCM1 & NCAR Parallel Climate Model, version 1 (United States) \\
Russia_INMCM3 & Institute of Numerical Mathematics (INM) Coupled Model, version 3.0 (Russia) \\
UKMO_HadCM3 & Met Office Hadley Centre, HadCM3 (United Kingdom) \\
UKMO_HadGEM1 & Met Office Hadley Centre, HadGEM1 (United Kingdom) \\
\hline
\end{tabular}

moisture and energy from the planetary boundary layer (PBL) to the free atmosphere, which supports the development of deep convection (e.g., Sobel and Neelin 2006; Back and Bretherton 2009; Holloway and Neelin 2009). From the energy budget point of view, the circulation associated with shallow convection imports moist static energy into the lower troposphere, creating a favorable condition (i.e., an unstable atmosphere) for deep convection to develop (Sobel and Neelin 2006; Back and Bretherton 2009). Clearly, shallow convection is closely related to deep convection, the associated tropical circulation, and other atmospheric phenomenon such as MJO. Thus, we can expect impacts on tropical convection and circulation coming from shallow convection under global warming.

In this study, our target domain is confined to climatologically convective regions with positive precipitation anomalies. The rest of the convective regions with negative rainfall anomalies are usually accompanied by weakened upward motion, mainly due to the import of dry advection from subsidence regions (Chou and Neelin 2004; Chou et al. 2009), and therefore are not discussed in the main content of this paper. However, we also examined the energy budget corresponding to this weakened upward motion; this shows a consistent result and has been provided in Fig. S3 of the supplemental material. The multimodel datasets that we have analyzed and the definition and estimation method for the study region are described in section 2. We diagnose changes in the moist static energy (MSE) budget and sea surface temperature (SST) associated with the intensity change in convection and vertical motion in section 3. From a qualitative perspective, further examinations of the vertical structure's impacts on changes in atmospheric stability and the associated circulation change are presented in section 4 . Finally, the impacts of shallow convection on circulation change are discussed in section 5 , followed by conclusions in section 6 .

\section{Data}

The World Climate Research Programme (WCRP) Coupled Model Intercomparison Project phase 3 (CMIP3; Meehl et al. 2007a; see also http://www-pcmdi. llnl.gov/ipcc/about_ipcc.php) and phase 5 (CMIP5; Taylor et al. 2012; see also http://cmip-pcmdi.llnl.gov/cmip5/index. html) multimodel datasets were used in this study. All results were calculated from monthly averages in the tropics $\left(30^{\circ} \mathrm{S}-30^{\circ} \mathrm{N}\right)$. The simulations of 32 models from CMIP3 and CMIP5 were used because of the availability of data and also the diversity of research organizations. The models from the CMIP3 and CMIP5 archives are listed in Table 1 and Table 2, respectively. The last 20 years of the 20C3M run in CMIP3 (1980-99) and the historical run in CMIP5 (1986-2005) are defined as the current climate, while the period of 2080-99 in the A1B scenario of CMIP3 and the representative concentration pathway 8.5 (RCP8.5) scenario of CMIP5 are defined as the future climate. Since the spatial pattern of changes in regional precipitation and circulation show low agreement among the GCMs, each model was examined individually to keep its uniqueness.

In this study, we focus on convective regions with positive precipitation anomalies, where the climatological environment and changes in precipitation are similar. The definitions of convective areas and changes in circulation are the same as those used in Chou et al. (2009). Convective regions are defined as areas with $-\left\langle\bar{\omega} \partial_{p} \bar{q}\right\rangle>0$ (e.g., Fig. 1b), where $\omega$ is the pressure vertical velocity and $q$ is the specific humidity. The convective regions defined by $-\left\langle\bar{\omega} \partial_{p} \bar{q}\right\rangle>0$ are very 
TABLE 2. As in Table 1, but for CMIP5.

\begin{tabular}{ll}
\hline \hline \multicolumn{1}{c}{ Model } & \multicolumn{1}{c}{ Description } \\
\hline ACCESS1.0 & Commonwealth Scientific and Industrial Research Organisation, and Bureau of Meteorology (Australia) \\
BCC_CSM1.1 & Beijing Climate Center, China Meteorological Administration (China) \\
CanESM2 & Canadian Centre for Climate Modelling and Analysis (Canada) \\
CESM1 (BGC) & NSF-DOE-NCAR, Community Earth System Model, version 1, with biogeochemistry (United States) \\
CNRM-CM5 & Centre National de Recherches Météorologiques/Centre Européen de Recherche et Formation Avancées \\
& en Calcul Scientifique (France) \\
FGOALS-s2 & LASG, Institute of Atmospheric Physics, Chinese Academy of Sciences (China) \\
GFDL CM3 & NOAA/Geophysical Fluid Dynamics Laboratory (United States) \\
GFDL-ESM2M & NOAA/Geophysical Fluid Dynamics Laboratory (United States) \\
HadGEM2-ES & Met Office Hadley Centre (United Kingdom) \\
IPSL-CM5A-LR & L'Institut Pierre-Simon Laplace (France) \\
IPSL-CM5A-MR & L'Institut Pierre-Simon Laplace (France) \\
MIROC5 & Atmosphere and Ocean Research Institute (The University of Tokyo), National Institute for Environ- \\
& mental Studies, and Japan Agency for Marine-Earth Science and Technology (Japan) \\
MIROC-ESM & Japan Agency for Marine-Earth Science and Technology, Atmosphere and Ocean Research Institute \\
& (The University of Tokyo), and National Institute for Environmental Studies (Japan) \\
MPI-ESM-LR & MPI-M (Germany) \\
MRI-CGCM3 & Meteorological Research Institute (Japan) \\
NorESM1-M & Norwegian Climate Centre (Norway) \\
\hline
\end{tabular}

similar to those using $\omega_{500 \mathrm{hPa}}=0$. In other words, convective regions are dominated by the convergence of mean moisture flux associated with mean upward motion. In the convective regions with positive rainfall anomalies (PC), which is our target domain, the strength of the corresponding tropical circulation can be either strengthened (SPC; i.e., $-\left\langle\omega^{\prime} \partial_{p} \bar{q}\right\rangle>0$ ) or weakened (WPC; i.e., $-\left\langle\omega^{\prime} \partial_{p} \bar{q}\right\rangle<0$; Fig. 1c). The prime is the difference between the current and future climate. Thus, a vertical integration of the change in tropical circulation is considered not as just a single layer but one with stronger weighting in the lower troposphere. The detailed descriptions of SPC and WPC are listed in Table 3. After defining from January to December, the annual SPC and WPC areas, changes in the vertical structure and MSE budget associated with regional circulation variability are each analyzed within the corresponding domain.

\section{Moist static energy budget}

\section{a. Vertical structure of vertical velocity}

Figure 2 illustrates the vertical structure of vertical velocity averaged over the SPC and WPC areas from the CMIP5 models. All models show a common vertical structure of mean vertical velocity for ascending motion in convective areas (Figs. 2a,b). Changes in vertical velocity, on the other hand, show almost opposite results between these two areas. Over the SPC areas, negative anomalies of vertical velocity exist in the entire column, representing a strengthening of the corresponding upward motion (Fig. 2c). Over the WPC areas, negative anomalies are found only in the upper troposphere above $300 \mathrm{hPa}$. Most of the troposphere is dominated by positive anomalies (Fig. 2d), implying a weakening of the corresponding ascending motion and an uplifting structure of convection (i.e., a deepening of convection). These vertical velocity characteristics can also been found in CMIP3 models (see Fig. S4 in the supplemental material).

\section{b. MSE budget}

Here, we first diagnose the MSE budget in order to understand the possible mechanisms related to the two different circulation changes between the SPC and WPC areas. The MSE budget has previously been used to study the energy sources associated with anomalous vertical motion for tropical convection (Chou and Neelin 2004; Chou et al. 2009; Chou and Chen 2010). The anomalous MSE budget can be written as follows:

TABLE 3. Definition of the SPC and WPC areas.

\begin{tabular}{lccc}
\hline \hline Areas & Climatological condition & Precipitation anomalies & Change in circulation \\
\hline SPC & Convective areas & Prec $^{\prime}>0$ & Strengthened \\
& $-\left\langle\bar{\omega} \partial_{p} \bar{q}\right\rangle>0$ & & $-\left\langle\omega^{\prime} \partial_{p} \bar{q}\right\rangle>0$ \\
WPC & Convective areas & $\operatorname{Prec}^{\prime}>0$ & Weakened \\
& $-\left\langle\bar{\omega} \partial_{p} \bar{q}\right\rangle>0$ & & $-\left\langle\omega^{\prime} \partial_{p} \bar{q}\right\rangle<0$ \\
\hline
\end{tabular}



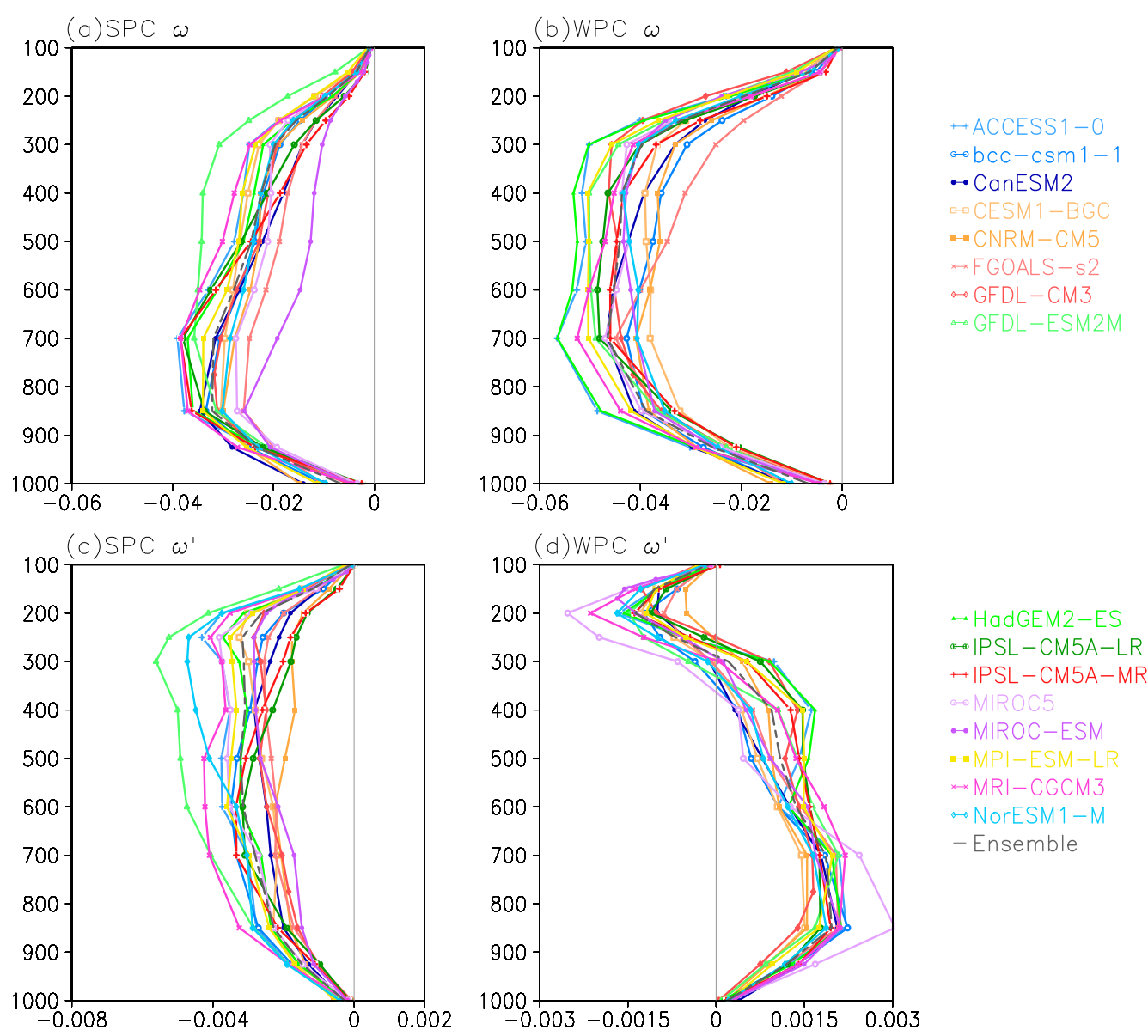

FIG. 2. Vertical profiles of the monthly mean vertical velocity $\left(\mathrm{Pa} \mathrm{s}^{-1}\right)$ from the 16 CMIP5 models in the current climate in (a) SPC and (b) WPC areas. Differences in vertical velocity $\left(\mathrm{Pa} \mathrm{s}^{-1}\right)$ between the future and current climate in the (c) SPC and (d) WPC areas in the models. The gray dashed lines denote the ensemble mean.

$$
\left\langle\omega \partial_{p} h\right\rangle^{\prime}=-\langle\mathbf{v} \cdot \nabla(T+q)\rangle^{\prime}+F^{\mathrm{net}^{\prime}}+\text { residual, }
$$

where the angle brackets \langle\rangle indicate a vertical integration from 1000 to $100 \mathrm{hPa}$. Assuming the residual contributions, such as nonlinear terms, the transient eddy, atmospheric storage, and transformation of data coordinate, are relatively small (Chou et al. 2009), the anomalous MSE budget then can be expressed as

$$
\left\langle\omega \partial_{p} h\right\rangle^{\prime} \approx-\langle\mathbf{v} \cdot \nabla(T+q)\rangle^{\prime}+F^{\mathrm{net}^{\prime}},
$$

which can be further decomposed to yield

$$
\left\langle\omega^{\prime} \partial_{p} \bar{h}\right\rangle \approx-\left\langle\bar{\omega} \partial_{p} h^{\prime}\right\rangle-\langle\mathbf{v} \cdot \nabla(T+q)\rangle^{\prime}+F^{\mathrm{net}^{\prime}} .
$$

The term $h$ is the MSE and $\mathbf{v}$ is the horizontal wind vector. The terms $T$ and $q$ are temperature and specific humidity in energy units $\left(\mathrm{J} \mathrm{kg}^{-1}\right)$ by multiplying the heat capacity at constant pressure $C_{p}$ and latent heat per unit mass $L$, respectively. The changes in net energy flux into the atmospheric column $F^{\text {net }}$ are balanced between longwave (LW) and shortwave (SW) radiative fluxes, as well as evaporation $E$ and sensible heat $H$ at the earth's surface:

$$
F^{\mathrm{net}^{\prime}}=\mathrm{LW}^{\prime}+\mathrm{SW}^{\prime}+E^{\prime}+H^{\prime} .
$$

From the MSE budget in (3), the change in vertical advection of MSE due to anomalous vertical velocity $\left\langle\omega^{\prime} \partial_{p} \bar{h}\right\rangle$ is approximately the sum of the change in MSE vertical advection due to an anomalous $h:-\left\langle\bar{\omega} \partial_{p} h^{\prime}\right\rangle$, horizontal temperature and moisture advection $-\langle\mathbf{v} \cdot \nabla(T+q)\rangle^{\prime}$, and the anomalous net flux into the atmosphere $F^{\text {net' }}$. Physically, the term $\left\langle\omega^{\prime} \partial_{p} \bar{h}\right\rangle$ is mainly associated with changes in tropical circulation, while $-\left\langle\bar{\omega} \partial_{p} h^{\prime}\right\rangle$ can represent changes in atmospheric stability (Chou et al. 2013). The term $F^{\text {net' }}$ is associated with cloud radiation and boundary condition, including surface latent and sensible heat fluxes. Each term 

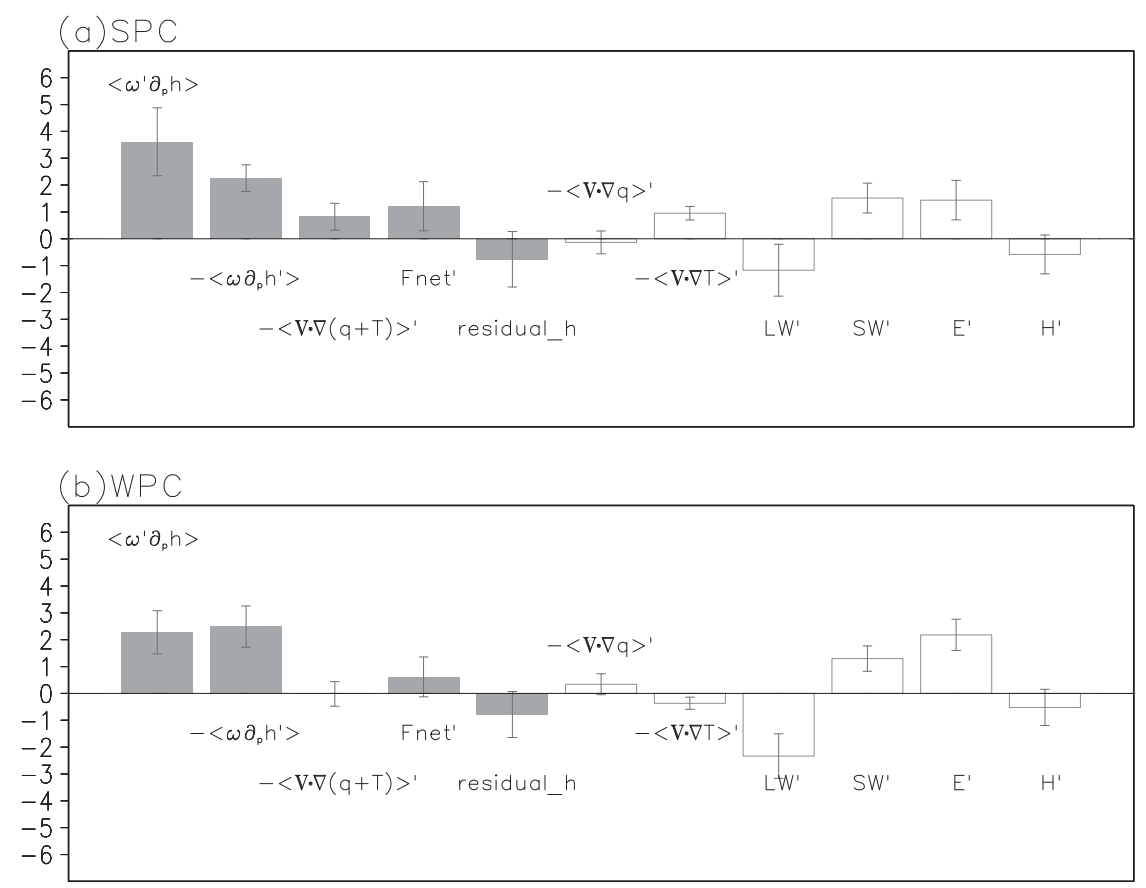

FIG. 3. Moist static energy budget terms $\left(\mathrm{Wm}^{-2}\right.$; gray shaded bars) averaged over the (a) SPC and (b) WPC areas. The bars are the ensemble means of 32 models from CMIP3 and CMIP5, and the error whiskers indicate the one SD values of the 32 models. The unshaded bars are the components of $-\langle\mathbf{v} \cdot \nabla(T+q)\rangle^{\prime}$ and $F^{\text {net' }}\left(\mathrm{W} \mathrm{m}^{-2}\right)$.

in (3) and (4) averaged over the SPC and WPC areas from the CMIP3 and CMIP5 simulations is presented as an ensemble averaged with error whiskers of one standard deviation (SD) in Fig. 3.

We first consider the entire study domain without dividing it into the SPC and WPC areas. Generally, the positive $\left\langle\omega^{\prime} \partial_{p} \bar{h}\right\rangle$ (Fig. 3a,b) is mainly contributed by the positive $-\left\langle\bar{\omega} \partial_{p} h^{\prime}\right\rangle$ and $F^{\text {net' }}$; the $-\langle\mathbf{v} \cdot \nabla(T+q)\rangle^{\prime}$ shows relatively smaller values in most models. The residual term is also smaller and tends to show negative values among the models. Under global warming, in other words, the increase in the export of MSE induced by changes in tropical circulation is mainly related to the decrease in atmospheric stability, which is equivalent to the "rich-getricher" mechanism (Chou and Neelin 2004; Chou et al. 2009), and the increase in the net energy into the atmosphere. Based on (4), positive $F^{\text {net' }}$ is mainly associated with positive evaporation anomalies induced by warmer SST and greater solar absorption due to increased water vapor (Fig. 1a). The longwave radiation $\mathrm{LW}^{\prime}$ is negative because of the warmer troposphere. The sensible heat tends to be slightly negative because of greater increases in atmospheric temperature than in SST.

We next examine the differences between the SPC and WPC regions. In the SPC regions, $\left\langle\omega^{\prime} \partial_{p} \bar{h}\right\rangle$ is positive with an average magnitude of about $3.6 \mathrm{~W} \mathrm{~m}^{-2}$ and one
SD ranging from 2.3 to $4.9 \mathrm{~W} \mathrm{~m}^{-2}$ for most models. A positive $\left\langle\omega^{\prime} \partial_{p} \bar{h}\right\rangle$ is expected because $\omega^{\prime}<0$ and it is the upper-tropospheric contribution that determines the sign. In the WPC regions, however, $\left\langle\omega^{\prime} \partial_{p} \bar{h}\right\rangle$ is smaller but still positive for most of the models, with a magnitude of $2.27 \mathrm{~W} \mathrm{~m}^{-2}$ and one SD ranging from 1.5 to $3 \mathrm{~W} \mathrm{~m}^{-2}$. It is clear that positive values of $\left\langle\omega^{\prime} \partial_{p} \bar{h}\right\rangle$ are not expected since $\omega^{\prime}>0$ in most of the troposphere (Fig. 2d) over the WPC regions. Positive $\omega^{\prime} \partial_{p} \bar{h}$ (see Figs. $2 \mathrm{~d}$ and 10a in the layers above $300 \mathrm{hPa}$ due to $\omega^{\prime}<0$ weakens the contribution of the negative $\omega^{\prime} \partial_{p} \bar{h}$ from the midtroposphere, which is induced by $\omega^{\prime}>0$ and leads to smaller positive $\left\langle\omega^{\prime} \partial_{p} \bar{h}\right\rangle$ values over the WPC areas. Thus, positive $\left\langle\omega^{\prime} \partial_{p} \bar{h}\right\rangle$ is found in both SPC and WPC areas, with slightly greater magnitudes in the SPC than WPC areas, even though the changes in the structure of vertical velocity are very different between these two areas. In other words, $\left\langle\omega^{\prime} \partial_{p} \bar{h}\right\rangle$ cannot be solely used to represent the change of sign in vertical velocity, at least in the current MSE budget.

We further examine the terms on the right-hand side of (3). The quantity $-\left\langle\bar{\omega} \partial_{p} h^{\prime}\right\rangle$ is very similar in both the SPC and WPC areas; it has an average of $2.25 \mathrm{~W} \mathrm{~m}^{-2}$ (with one SD between 1.7 and $2.7 \mathrm{~W} \mathrm{~m}^{-2}$ ) in the SPC area and an average of $2.5 \mathrm{~W} \mathrm{~m}^{-2}$ (with one SD between $1.7 \mathrm{~W} \mathrm{~m}^{-2}$ and $3.2 \mathrm{~W} \mathrm{~m}^{-2}$ ) in the WPC area. In the SPC 
areas, the changes in horizontal temperature and moisture advection $-\langle\mathbf{v} \cdot \nabla(T+q)\rangle^{\prime}$ tend to be of a smaller positive value in most models with an averaged magnitude of $0.8 \mathrm{~W} \mathrm{~m}^{-2}$ and one SD between 0.3 and $1.32 \mathrm{~W} \mathrm{~m}^{-2}$. In the WPC areas, both positive and negative anomalous horizontal advection exists among the models; therefore, this results in a smaller average of $-0.02 \mathrm{~W} \mathrm{~m}^{-2}$ with one SD between $\pm 0.4 \mathrm{~W} \mathrm{~m}^{-2}$. Further examining the difference in $-\langle\mathbf{v} \cdot \nabla(T+q)\rangle^{\prime}$ between the SPC and WPC areas, one finds that it is mainly due to $-\langle\mathbf{v} \cdot \nabla T\rangle^{\prime}$ (Fig. 3, outlined bar). The $-\langle\mathbf{v} \cdot \nabla q\rangle^{\prime}$ is relatively smaller than $-\langle\mathbf{v} \cdot \nabla T\rangle^{\prime}$ and tends to show both positive and negative contributions among models for these two areas. The difference in $-\langle\mathbf{v} \cdot \nabla T\rangle^{\prime}$ between SPC and WPC areas is mainly due to the opposite change in the horizontal flow $\left(-\left\langle\mathbf{v}^{\prime} \cdot \nabla T\right\rangle\right.$; not shown), which is associated and consistent with an opposite change in vertical velocity. This further leads to a more positive (negative) $-\langle\mathbf{v} \cdot \nabla T\rangle^{\prime}$ in the SPC (WPC) areas. The changes in horizontal temperature advection due to increased temperature $\left(-\left\langle\mathbf{v} \cdot \nabla T^{\prime}\right\rangle\right)$, however, are positive in both the SPC and WPC areas (not shown).

The $F^{\text {net' }}$ is positive in the two areas. It has an average of $1.2 \mathrm{~W} \mathrm{~m}^{-2}$ in the SPC area and a smaller magnitude of $0.6 \mathrm{~W} \mathrm{~m}^{-2}$ in the WPC area. The corresponding one SD ranges from 0.3 to $2.1 \mathrm{~W} \mathrm{~m}^{-2}$ and -0.12 to $1.3 \mathrm{~W} \mathrm{~m}^{-2}$ in the SPC and WPC areas, respectively. Further examining the four terms on the right-hand side of (4), the greater $F^{\text {net' }}$ in the SPC area is mainly related to the greater (smaller) LW' in the SPC (WPC) area (Fig. 3, outlined bar), which implies a less (more) longwave radiation flux emitted from the atmosphere. The different $\mathrm{LW}^{\prime}$ between these two areas is mainly caused by less outgoing longwave radiation OLR' in the SPC than in the WPC area (not shown); this might be related to the increased cloud amount, higher cloud top, and lower cloud-top temperature associated with the strengthened convection in the SPC area. The changes in solar absorption and sensible heat flux show similar results in the SPC and WPC areas.

We have also considered the boundary condition associated with the departures from the tropical average of the SST anomalies (Fig. 4). The change in the SST pattern in most models tends to distribute warmer anomalies in the SPC than in the WPC area, showing a range from about 0 to $0.4 \mathrm{~K}$ in the SPC area and from -0.05 to $0.2 \mathrm{~K}$ in the WPC area. This larger (smaller) warmer anomaly in the strengthened (weakened) area is consistent with previous studies (e.g., Ma et al. 2012; Ma and Xie 2013). This implies that the boundary condition associated with the SST pattern change may have an impact on regional changes in vertical velocity, although the magnitude of the differences between the strengthened and weakened area is smaller in this study.

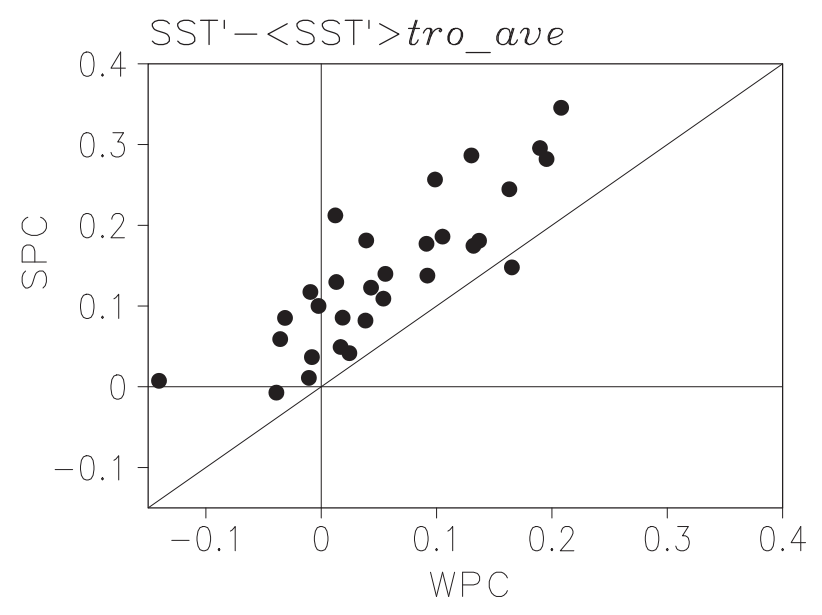

FIG. 4. The scatterplot for the change in the SST pattern (K; SST minus tropical mean $\mathrm{SST}^{\prime}$ ) in the SPC vs WPC area from a total of 32 CMIP3 and CMIP5 models. The unit is K.

The analysis of the MSE budget associated with convection shows that is it is slightly imbalanced due to nonlinear and transient terms, atmospheric storage, and the errors due to transformation from the original to the standard pressure coordinate (Chou and Chen 2010; Neelin 2007; I. Held 2015, personal communication); however, some effects clearly stand out above the rest. Overall, $-\left\langle\bar{\omega} \partial_{p} h^{\prime}\right\rangle$ and $F^{\text {net' }}$ are the larger terms contributing to the MSE convergence associated with $\omega^{\prime}$. The former is related to the decrease in atmospheric stability induced by a more humid atmosphere, especially in the lower troposphere, which is consistent with the rich-getricher mechanism (Chou and Neelin 2004; Chou et al. 2009). The latter is related to the boundary condition associated with warmer SSTs and a moister atmosphere. From a regional perspective, the change in the SST pattern seems to provide an anomalous boundary condition favoring the change in the regional circulation.

Examining the energy budget related to an anomalous circulation, the opposite response of anomalous circulation was, however, not found in the $\left\langle\omega^{\prime} \partial_{p} \bar{h}\right\rangle$ term. It shows positive value in both areas with larger magnitude in the SPC than in the WPC area. The consistent column-strengthened vertical velocity produces a larger positive $\left\langle\omega^{\prime} \partial_{p} \bar{h}\right\rangle$ in the SPC area (Figs. 2c and 10a). On the other hand, the strengthened upward motion over the upper troposphere in the WPC area (Figs. $2 \mathrm{~d}$ and 10a) provides a positive contribution and counteracts the negative contribution from the weakened vertical velocity over the lower to midtroposphere. This cancellation further results in a smaller positive $\left\langle\omega^{\prime} \partial_{p} \bar{h}\right\rangle$ in the WPC area. The $-\left\langle\bar{\omega} \partial_{p} h^{\prime}\right\rangle$ is the largest term with similar magnitude in the two areas. The $-\langle\mathbf{v} \cdot \nabla(T+q)\rangle^{\prime}$ and $F^{\text {net' }}$ terms both have greater positive contribution 
to $\left\langle\omega^{\prime} \partial_{p} \bar{h}\right\rangle$ in SPC than in the WPC area. The additional anomalous energy is related to the corresponding strengthened and weakened convection.

Although the anomalous energy budget is different between the SPC and WPC areas, the changes in vertical transport of MSE related to the opposite anomalous circulation (i.e. $\left\langle\omega^{\prime} \partial_{p} \bar{h}\right\rangle$ ) being both positive, does not show the correspondingly opposite expected result. In other words, the diverse response in the corresponding tropical circulation $\omega^{\prime}$ [i.e., the strengthened (weakened) upward circulation in the SPC (WPC) area] is not capable of being explained and directly distinguished from the change in MSE budget in these two areas. The complex structure of vertical velocity has a potential impact on the results of vertical transport of MSE; this prompted us to further clarify the role of vertical structure on changes in atmospheric circulation and stability. The atmospheric stability represents a collection of the information on whether the atmospheric condition and vertical structure favor the strengthening or weakening of convection. Here, the vertical advection associated with increased MSE $-\left\langle\bar{\omega} \partial_{p} h^{\prime}\right\rangle$ is related to changes in atmospheric stability (Chou and Chen 2010; Chou et al. 2013), which also shows a consistent positive tendency. Thus, from a qualitative perspective, we further examine the possible impact of the vertical structure of vertical velocity on the change in circulation as well as the corresponding change in stability in the following section.

\section{Impacts of vertical structure of convection}

\section{a. Decomposition of vertical velocity}

In general, the vertical velocity associated with deep convection can be decomposed into its strength and its vertical profile (e.g., Neelin and Zeng 2000; Chou and Neelin 2004; Back and Bretherton 2009), so the vertical velocity $\omega$ can be expressed as follows:

$$
\omega=-\Omega(p) \nabla \cdot \mathbf{v}_{T}(x, y),
$$

where $\Omega(p)$ is the vertical profile of vertical velocity and the divergence term $\nabla \cdot \mathbf{v}_{T}(x, y)$ can be used to represent the strength of vertical velocity. In (5), $\Omega(p)$ is estimated from $\omega$ by a normalization using the vertical integral of its corresponding intensity at each level; that is, $\Omega(p)=|\omega| / \sqrt{\left(\sum_{i=P_{s}}^{P_{t}} \omega_{i}^{2} \delta p_{i}\right) \Delta P^{-1}}$. The terms $P_{s}$ and $P_{t}$ are the pressure at the surface and the tropopause, respectively. The term $\delta p_{i}$ is the depth of each layer and $\Delta P$ is the whole column depth (i.e., $P_{s}-P_{t}$ ), which is from 1000 to $100 \mathrm{hPa}$ here. Since $\Omega(p)$ is defined positive, a positive $\nabla \cdot \mathbf{v}_{T}(x, y)$ represents low-level convergence and upper-level divergence, corresponding to an upward motion. Thus, the difference in $\omega$ between the current and future climate can then be approximated as follows:

$$
\omega^{\prime} \approx-\Omega^{\prime} \nabla \cdot \overline{\mathbf{v}}_{T}-\bar{\Omega} \nabla \cdot \mathbf{v}_{T}^{\prime},
$$

where the nonlinear term is assumed to be relatively small. The first term on the right-hand side of (6) (i.e., $\left.-\Omega^{\prime} \nabla \cdot \overline{\mathbf{v}}_{T}\right)$ denotes the contribution from changes in the vertical profile of vertical velocity, and the second term (i.e., $-\bar{\Omega} \nabla \cdot \mathbf{v}_{T}^{\prime}$ ) represents the contribution from changes in the intensity of vertical velocity.

First of all, the climatological vertical profile of vertical velocity $\bar{\Omega}$, averaged over the SPC and WPC areas from CMIP3 and CMIP5 models, is examined and shown in Fig. 5 . In the SPC area, $\bar{\Omega}$ tends to distribute a bottom-heavy-like structure with in most models, the strongest upward motion from around 900 to $700 \mathrm{hPa}$ (Figs. 5a,c). In the WPC area, on the other hand, the vertical profile of vertical velocity shows a deeper development. The strongest upward motion is between 700 and $300 \mathrm{hPa}$ and tends to show a top-heavy structure in most models (Figs. 5b,c).

Based on (6), changes in the decomposed vertical velocity of CMIP3 and CMIP5 are shown in Fig. 6. The changes in vertical velocity due to changes in vertical profile (i.e., $-\Omega^{\prime} \nabla \cdot \overline{\mathbf{v}}_{T}$ ) show similar patterns and scales between the SPC and WPC areas in almost all models (Figs. 6a,c,e,g), with an ensemble between -1 and $10^{-3} \mathrm{~Pa} \mathrm{~s}^{-1}$. A downward anomaly is found over the lower to midtroposphere. However to the contrary, an upward anomaly exists above $500 \mathrm{hPa}$, with a maximum at around $200 \mathrm{hPa}$. This implies that an uplifting of upward motion and a deepening of convection occur in both the SPC and WPC areas. In fact, this deepening of convection is found in almost the entire tropics (Chou et al. 2013). The changes in the strength of vertical velocity, $-\bar{\Omega} \nabla \cdot \mathbf{v}_{T}^{\prime}$, on the other hand, illustrate mirror-like patterns between the SPC and WPC areas (Figs. 6b,d,f,h). Negative $-\bar{\Omega} \nabla \cdot \mathbf{v}_{T}^{\prime}$ in the SPC areas represents an enhanced upward motion (i.e., $\nabla \cdot \mathbf{v}_{T}^{\prime}>0$ ), while positive $-\bar{\Omega} \nabla \cdot \mathbf{v}_{T}^{\prime}$ in the WPC areas indicates a reduced upward motion (i.e., $\nabla \cdot \mathbf{v}_{T}^{\prime}<0$ ). In other words, $-\bar{\Omega} \nabla \cdot \mathbf{v}_{T}^{\prime}$ can be used to represent changes of sign in vertical velocity in the SPC and WPC areas, unlike $\left\langle\omega^{\prime} \partial_{p} \bar{h}\right\rangle$ (Fig. 3). Aside from the mirror response, the magnitude of $-\bar{\Omega} \nabla \cdot \mathbf{v}_{T}^{\prime}$ is much weaker in the WPC than SPC areas, being only a quarter of that in the SPC areas.

In the SPC areas, $-\bar{\Omega} \nabla \cdot \mathbf{v}_{T}^{\prime}$ is the dominant contribution, which tends to strengthen the circulation (Figs. 6b,f). Combining this with $-\Omega^{\prime} \nabla \cdot \overline{\mathbf{v}}_{T}$, which is larger than zero over the lower troposphere and less than zero over the upper troposphere, leads to a strengthening of 

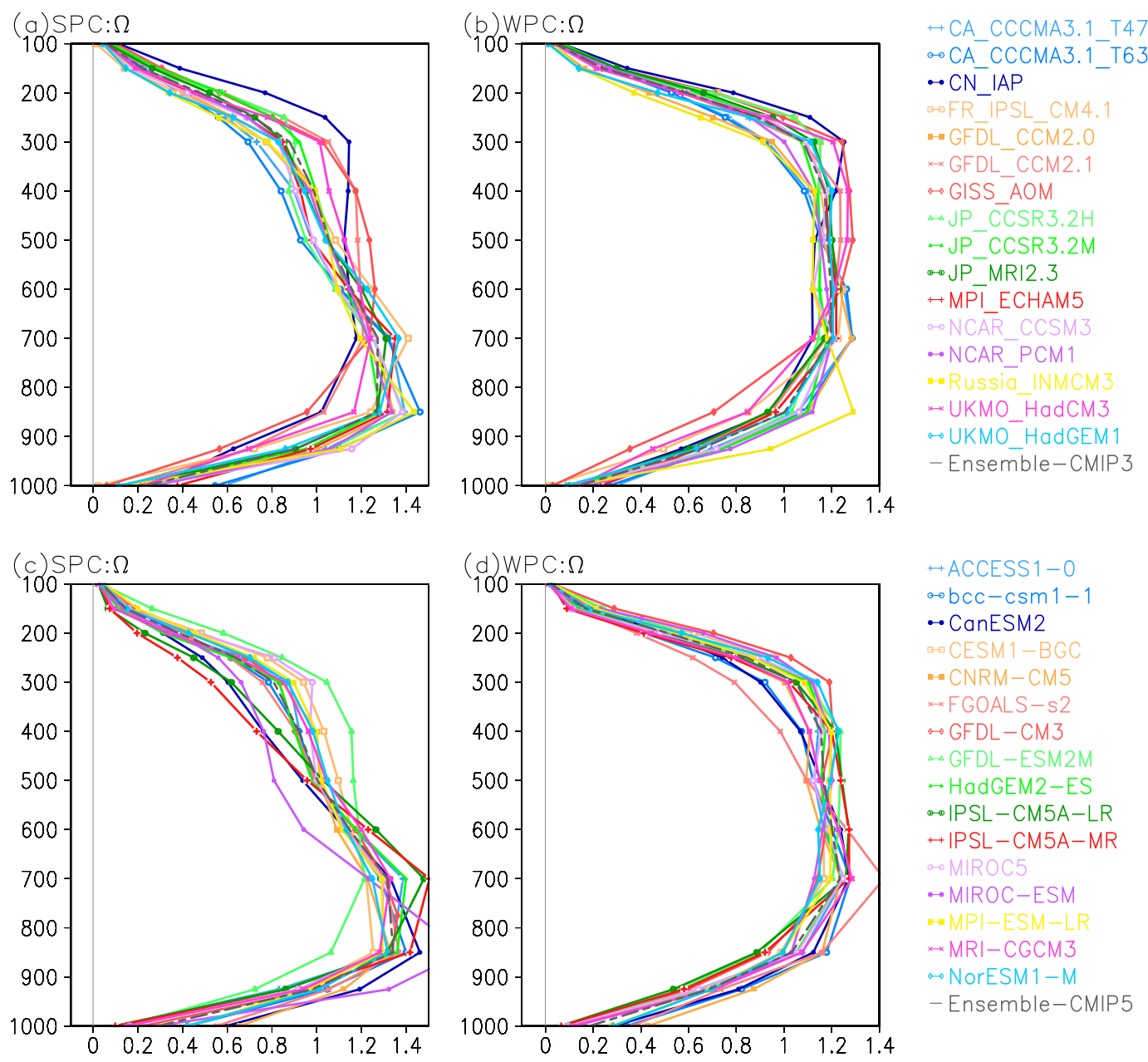

FIG. 5. Decomposed vertical profiles of mean vertical velocity in the current climate in the (a) SPC and (b) WPC areas from the CMIP3 model simulations. (c),(d) As in (a),(b), but from CMIP5. The gray dashed lines denote the ensemble mean.

ascending motion as shown in Fig. 2c. In the WPC area, on the other hand, $-\bar{\Omega} \nabla \cdot \mathbf{v}_{T}^{\prime}$ tends to reduce the circulation and has a much weaker amplitude, which is comparable to the amplitude of $-\Omega^{\prime} \nabla \cdot \overline{\mathbf{v}}_{T}$. This leads to the uplifting tendency of ascending motion shown in Fig. 2d. The decomposition of vertical velocity illustrates clear discrepancies in tropical convection changes as well as the characteristics of the climatological vertical profile between the SPC and WPC areas.

\section{b. The gross moist stability and change in circulation}

As discussed in the previous section, we would like to qualitatively further clarify the impact of the vertical structure of vertical velocity on the vertical transport of MSE on the change in circulation and the corresponding change in atmospheric stability. For this purpose, a simplified MSE budget is therefore considered as follows:

$$
\left\langle\omega^{\prime} \partial_{p} \bar{h}\right\rangle \approx-\left\langle\bar{\omega} \partial_{p} h^{\prime}\right\rangle .
$$

We note that (7) is not a complete MSE budget if considering the entire study domain. Implementing the decomposed vertical velocity shown in (5) and (6), (7) can be expressed as

$$
-\left\langle\left[\Omega^{\prime} \nabla \cdot \overline{\mathbf{v}}_{T}+\bar{\Omega} \nabla \cdot \mathbf{v}_{T}^{\prime}\right] \partial_{p} \bar{h}\right\rangle \approx\left\langle\bar{\Omega} \nabla \cdot \overline{\mathbf{v}}_{T} \partial_{p} h^{\prime}\right\rangle,
$$

which can be rearranged as

$$
-\left\langle\Omega^{\prime} \partial_{p} \bar{h}\right\rangle \nabla \cdot \overline{\mathbf{v}}_{T}-\left\langle\bar{\Omega} \partial_{p} \bar{h}\right\rangle \nabla \cdot \mathbf{v}_{T}^{\prime} \approx\left\langle\bar{\Omega} \partial_{p} h^{\prime}\right\rangle \nabla \cdot \overline{\mathbf{v}}_{T} .
$$

We next introduce the gross moist stability $M$ (Neelin and Yu 1994; Yu and Neelin 1997; Yu et al. 1998; Chou et al. 2013), defined as $M=-\left(g / P_{T}\right)\left\langle\Omega \partial_{p} h\right\rangle$, where $g$ is gravity and $P_{T}$ is the depth of the troposphere. In this study, $M$ (in $\mathrm{J} \mathrm{kg}^{-1} \mathrm{~Pa}^{-1}$ ) represents 

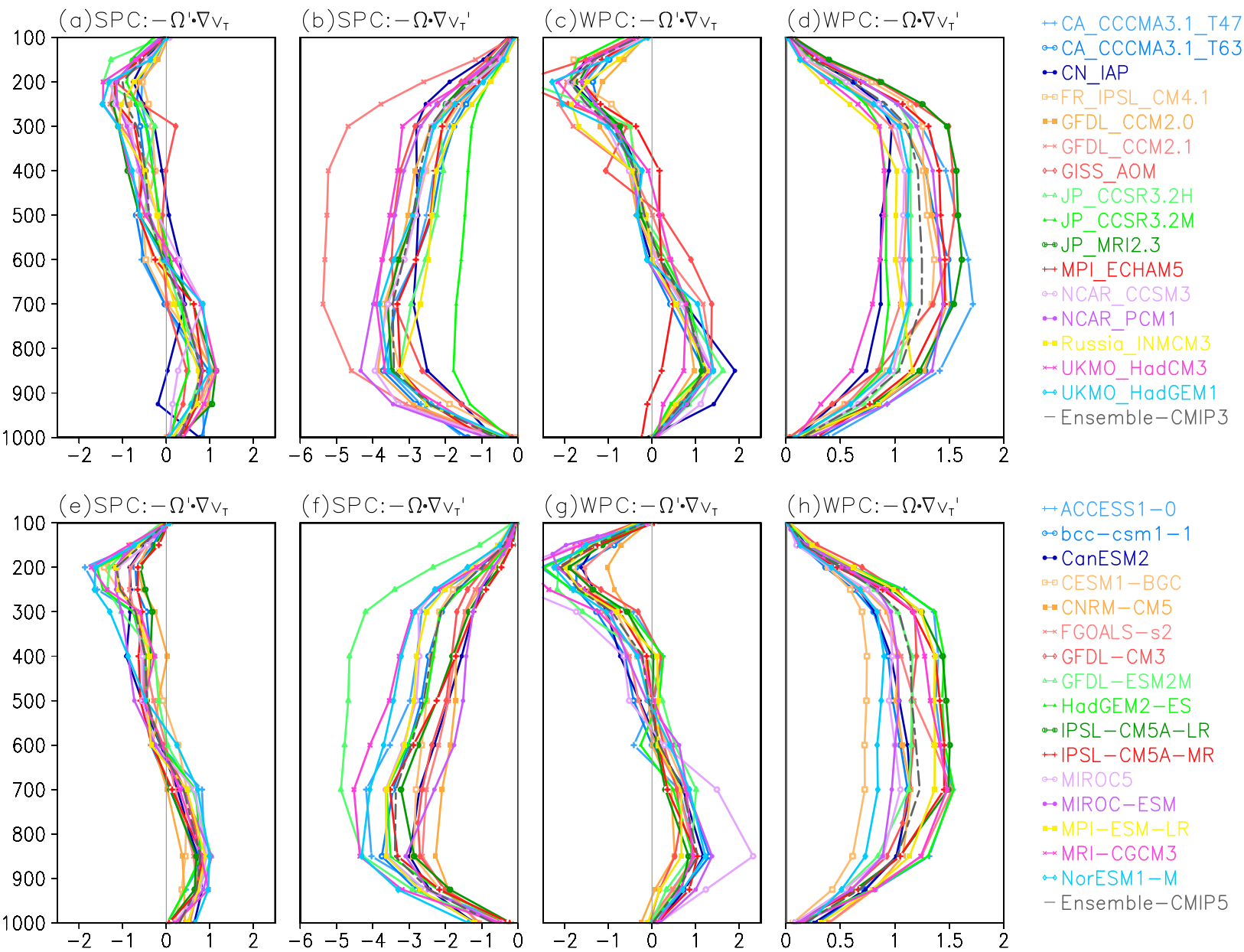

FIG. 6. Decomposed vertical profiles of changes in vertical velocity $\left(10^{-3} \mathrm{~Pa} \mathrm{~s}^{-1}\right)$. (top) Shown are the (a),(c) $-\Omega^{\prime} \nabla \cdot \overline{\mathbf{v}}_{T}$ and (b),(d) $-\bar{\Omega} \nabla \cdot \mathbf{v}_{T}^{\prime}$ over the SPC and WPC areas, respectively, from the CMIP3 model simulations. (bottom) As in (top), but from the CMIP5 model simulations $\left(\mathrm{J} \mathrm{kg}^{-1}\right)$. The gray dashed lines denote the ensemble mean.

the effective static stability, equivalent to how much energy associated with the integrated column is needed for per-unit upward motion in deep convection, which is slightly different from previous studies (i.e., $\mathrm{J} \mathrm{kg}^{-1}$ ). Accordingly, (9) can further be rewritten as follows:

$$
M_{\Omega}^{\prime} \nabla \cdot \overline{\mathbf{v}}_{T}+\bar{M} \nabla \cdot \mathbf{v}_{T}^{\prime} \approx-M_{h}^{\prime} \nabla \cdot \overline{\mathbf{v}}_{T},
$$

where $M_{h}^{\prime}=-\left(g / P_{T}\right)\left\langle\bar{\Omega} \partial_{p} h^{\prime}\right\rangle$ and $M_{\Omega}^{\prime}=-\left(g / P_{T}\right)\left\langle\Omega^{\prime} \partial_{p} \bar{h}\right\rangle$. The term $M_{h}^{\prime}$ represents the anomalies of the gross moist stability resulting from variations of $h$ (MSE), while $M_{\Omega}^{\prime}$ is the anomalous $M$ due to changes in the shape of the vertical velocity profile. With a rearrangement, (10) can be expressed as a form of relative change:

$$
\frac{\nabla \cdot \mathbf{v}_{T}^{\prime}}{\nabla \cdot \overline{\mathbf{v}}_{T}} \approx-\left(\frac{M_{h}^{\prime}}{\bar{M}}+\frac{M_{\Omega}^{\prime}}{\bar{M}}\right)
$$

In practice, the mean gross moist stability $\bar{M}$ is usually positive in the entire tropics (Yu et al. 1998; Chou et al. 2013), while $\nabla \cdot \overline{\mathbf{v}}_{T}$ is positive only in convective areas. The term on the left-hand side of (11) represents the rate of changes in the strength of tropical circulations. The first term on the right-hand side of (11) represents the fractional contribution from change in MSE profile, which is similar to the thermodynamic contribution. The second term on the right-hand side of (11) is associated with change in the shape of vertical velocity profile, which is a part of the dynamic contribution.

We first of all examine, Fig. 7a, which shows a scatterplot of mean gross moist stability in the SPC and WPC areas estimated from the CMIP3 and CMIP5 models. Generally, the quantity $\bar{M}$ shows positive values with a range from 0 to $0.2 \mathrm{~J} \mathrm{~kg}^{-1} \mathrm{~Pa}^{-1}$ in most models. Comparing the distribution between the SPC and WPC areas, $\bar{M}$ tends to be a smaller value in the SPC than in 

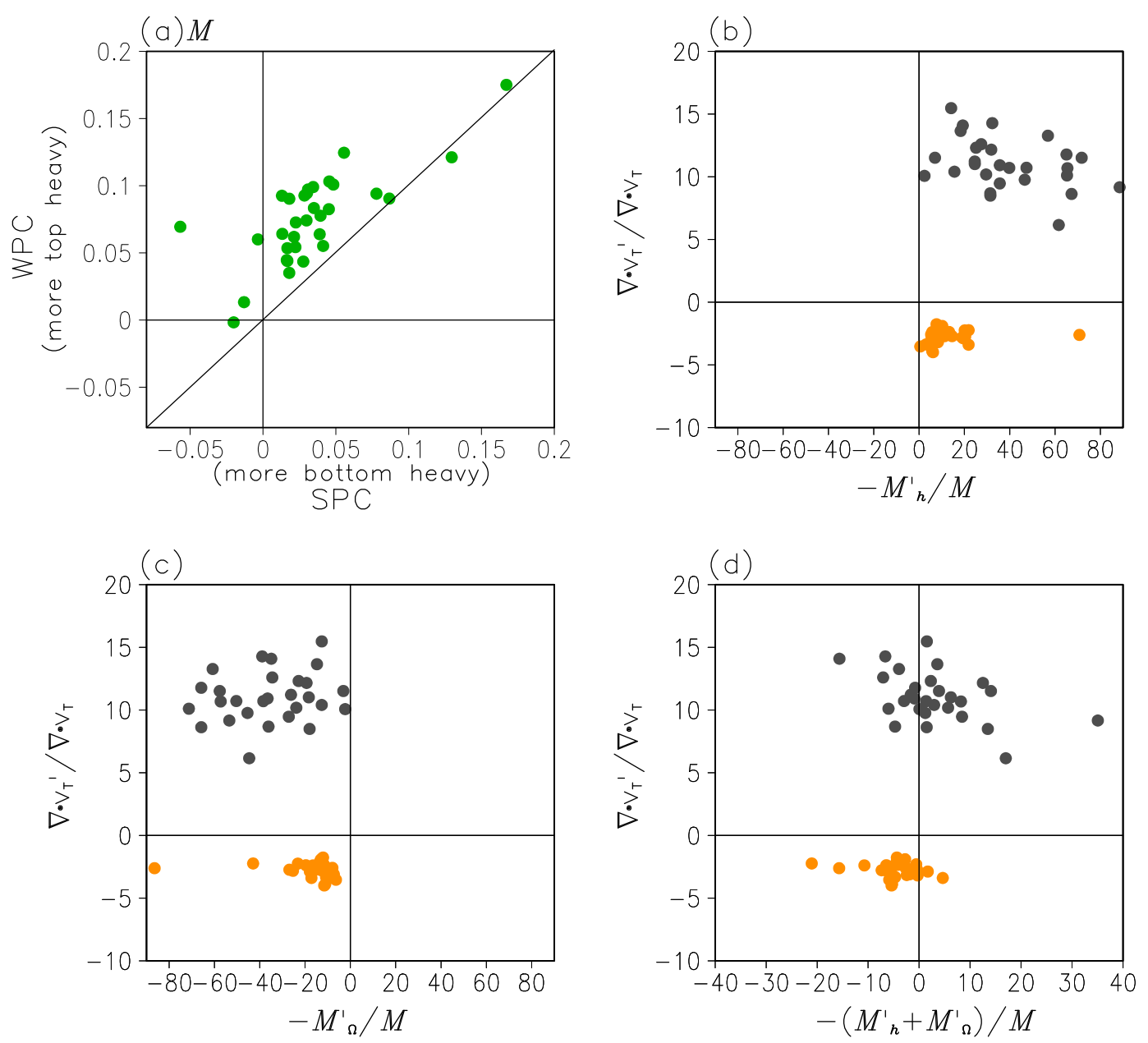

FIG. 7. Scatterplots for (a) $\bar{M}$ in the current climate in the SPC vs WPC areas $\left(\mathrm{J} \mathrm{kg}^{-1} \mathrm{~Pa}^{-1}\right)$ and the relative changes in terms of convergence $\nabla \cdot \mathbf{v}_{T}^{\prime} / \nabla \cdot \overline{\mathbf{v}}_{T}$ vs gross moist stability in (b) $-M_{h}^{\prime} / \bar{M}$ and (c) $-M_{\Omega}^{\prime} / \bar{M}$, and in (d) $-\left(M_{h}^{\prime}+M_{\Omega}^{\prime}\right) / \bar{M}$ in the SPC and WPC areas $\left(\% \mathrm{~K}^{-1}\right)$ from 32 models.

the WPC area. This is related to the difference in the mean vertical profiles of vertical velocity in these two areas, which shows a more bottom-heavy profile in the SPC area and a more top-heavy profile in the WPC area. The bottom-heavy profile tends to import MSE into the atmospheric column and implies a negative $M$, while the top-heavy profile exports MSE out of the atmospheric column and leads to a positive $M$ (Back and Bretherton 2006; Inoue and Back 2015b). In the SPC (WPC) area, $\bar{\Omega}$ shows a more bottom-heavy (top heavy) profile (Fig. 5) and further leads to a smaller (greater) $\bar{M}$. We also note that there are four models showing negative $\bar{M}$, which is related to the excessively bottom-heavy profile of $\bar{\Omega}$ in these models. To avoid this problem result from (11), we excluded those four models with $\bar{M}<0$ for the analysis results shown in Figs. 7b-d.

Unlike (3), (11) can be used to directly express and study the possible mechanisms related to the opposite circulation change. Figures $7 \mathrm{~b}-\mathrm{d}$ show a scatter distribution of the terms in (11) from CMIP3 and CMIP5. The changes in the strength of vertical velocity (i.e., $\left.\nabla \cdot \mathbf{v}_{T}^{\prime} / \nabla \cdot \overline{\mathbf{v}}_{T}\right)$ are all positive in the models in the SPC area (Figs. $7 b-d$ ) with a ratio of $5 \%$ to $15 \%$, which represents an enhanced low-level convergence and upper-level divergence. This implies a strengthening of the tropical circulation. In the WPC area, however, the negative change in $\nabla \cdot \mathbf{v}_{T}^{\prime} / \nabla \cdot \overline{\mathbf{v}}_{T}$ (Figs. 7b-d) with a ratio of $-5 \%$ to $0 \%$ shows a weakened low-level convergence and upper-level divergence. As a result, this implies a weakening of the tropical circulation. The changes in gross moist stability due to increased moist static energy show positive values in both the SPC and WPC areas (Fig. 7b). This indicates that the increased moist static energy decreases the gross moist stability and further provides an environment favoring the strengthening of convection. On the other hand, the change in gross moist 

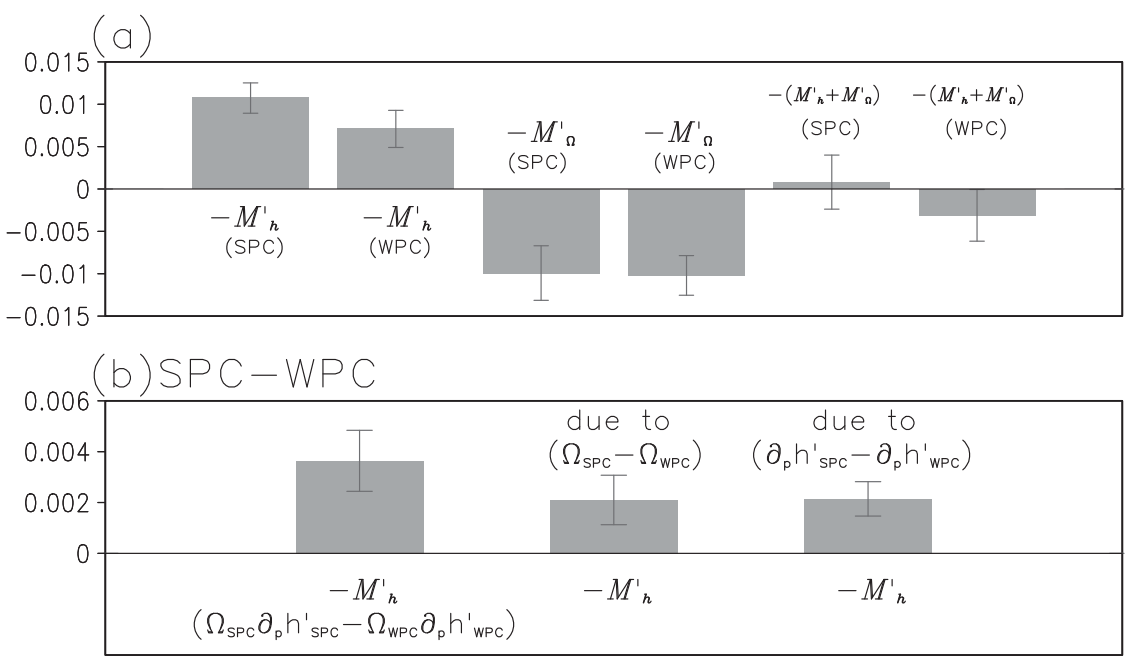

FIG. 8. As in Fig. 3, but for (a) changes in gross moist stability in (11) averaged over the SPC and WPC areas and (b) the $-M_{h}^{\prime}$ difference between the SPC and WPC areas and the differences of $-M_{h}^{\prime}$ due to $\Omega_{\mathrm{SPC}}-\Omega_{\mathrm{WPC}}$ and $\partial_{p} h_{\mathrm{SPC}}^{\prime}-\partial_{p} h_{\mathrm{WPC}}^{\prime}\left(\mathrm{J} \mathrm{kg}^{-1} \mathrm{~Pa}^{-1}\right)$.

stability due to $\Omega^{\prime}$ shows negative values in these two areas (Fig. $7 \mathrm{c}$ ). This represents a more stable environment that is unfavorable to circulation strengthening. The negative contribution associated with the increased gross moist stability is due to the uplifting of the vertical structure of vertical velocity (i.e., the deepening of convection; Figs. 6a,c,e,g). Since (11) has been simplified for the purpose of a qualitative discussion from the stability point of view, the combination effect of $M_{h}^{\prime}$ and $M_{\Omega}^{\prime}$ does not illustrate a clear positive and negative distribution (Fig. 7d) in the SPC and WPC areas. However, a tendency of more positive (negative) or greater (smaller) $-\left(M_{h}^{\prime}+M_{\Omega}^{\prime}\right) / \bar{M}$ values still can be found in SPC (WPC) as shown in Fig. 7d. This illustrates that the atmospheric environment tends to be more unstable and favorable for strengthening of convection in the SPC area. We note that the magnitude of change rate associated with anomalous $M$ is larger and more scattered in the SPC than in the WPC area because of the different mean $\bar{M}$ between these two areas (i.e., $\left.\bar{M}_{\mathrm{SPC}}<\bar{M}_{\mathrm{WPC}}\right)$. The different role of $M_{h}^{\prime}$ and $M_{\Omega}^{\prime}$ between these two areas is further investigated directly in Fig. 8.

The $-M_{h}^{\prime}$ shows positive anomalies in both the SPC and WPC areas but illustrates a larger average in the SPC area than the WPC area. The positive $-M_{h}^{\prime}$ represents decreased stability due to increased MSE, which favors the strengthening of circulation. The ensemble mean from 32 models of $-M_{h}^{\prime}$ is $0.01 \mathrm{~J} \mathrm{~kg}^{-1} \mathrm{~Pa}^{-1}$ with one SD from 0.008 to $0.012 \mathrm{~J} \mathrm{~kg}^{-1} \mathrm{~Pa}^{-1}$ in the SPC area and $0.007 \mathrm{~J} \mathrm{~kg}^{-1} \mathrm{~Pa}^{-1}$ with one SD from 0.004 to $0.009 \mathrm{~J} \mathrm{~kg}^{-1} \mathrm{~Pa}^{-1}$ in the WPC area. On the other hand, the negative $-M_{\Omega}^{\prime}$ values are found in both the SPC and WPC areas. The negative $-M_{\Omega}^{\prime}$ values represent increased stability due to changes in $\Omega$, which tends to weaken the upward motion in deep convection. The $-M_{\Omega}^{\prime}$ shows a similar magnitude of $-0.01 \mathrm{~J} \mathrm{~kg}^{-1} \mathrm{~Pa}^{-1}$ in these two areas, with one SD from -0.013 to $-0.006 \mathrm{~J} \mathrm{~kg}^{-1} \mathrm{~Pa}^{-1}$ and -0.012 to $-0.007 \mathrm{~J} \mathrm{~kg}^{-1} \mathrm{~Pa}^{-1}$ in the SPC and WPC areas, respectively. The combined change in gross moist stability, $-\left(M_{h}^{\prime}+M_{\Omega}^{\prime}\right)$, shows a small positive ensemble average in the SPC area, with one SD from -0.002 to $0.004 \mathrm{~J} \mathrm{~kg}^{-1} \mathrm{~Pa}^{-1}$. The averaged $-\left(M_{h}^{\prime}+M_{\Omega}^{\prime}\right)$ is $-0.003 \mathrm{~J} \mathrm{~kg}^{-1} \mathrm{~Pa}^{-1}$ in the WPC area, with one SD from -0.006 to $0 \mathrm{~J} \mathrm{~kg}^{-1} \mathrm{~Pa}^{-1}$. Comparing the difference in the quantity $-\left(M_{h}^{\prime}+M_{\Omega}^{\prime}\right)$ between these two areas, demonstrates that the gross moist stability tends to be more unstable (stable) in the SPC (WPC) area in most models, which implies an environment favorable (unfavorable) for convection strengthening. This difference is mainly due to the greater $-M_{h}^{\prime}$ in the SPC area. The difference in $-M_{h}^{\prime}$ between the SPC and WPC areas may depend on changes in either the MSE or the mean vertical structure of the vertical velocity $\bar{\Omega}$. The increased MSE, which is mainly associated with the increased water vapor, leads to a destabilization of the atmosphere and a strengthening of the ascending motion, which occurs in both the SPC and WPC areas. This convective feedback is consistent with the rich-getricher mechanism (Chou and Neelin 2004; Chou et al. 2009). The mean vertical structure of vertical velocity is associated with the partition of shallow and deep convection, such as bottom-heavy or top-heavy vertical velocity profiles (Back and Bretherton 2006). 

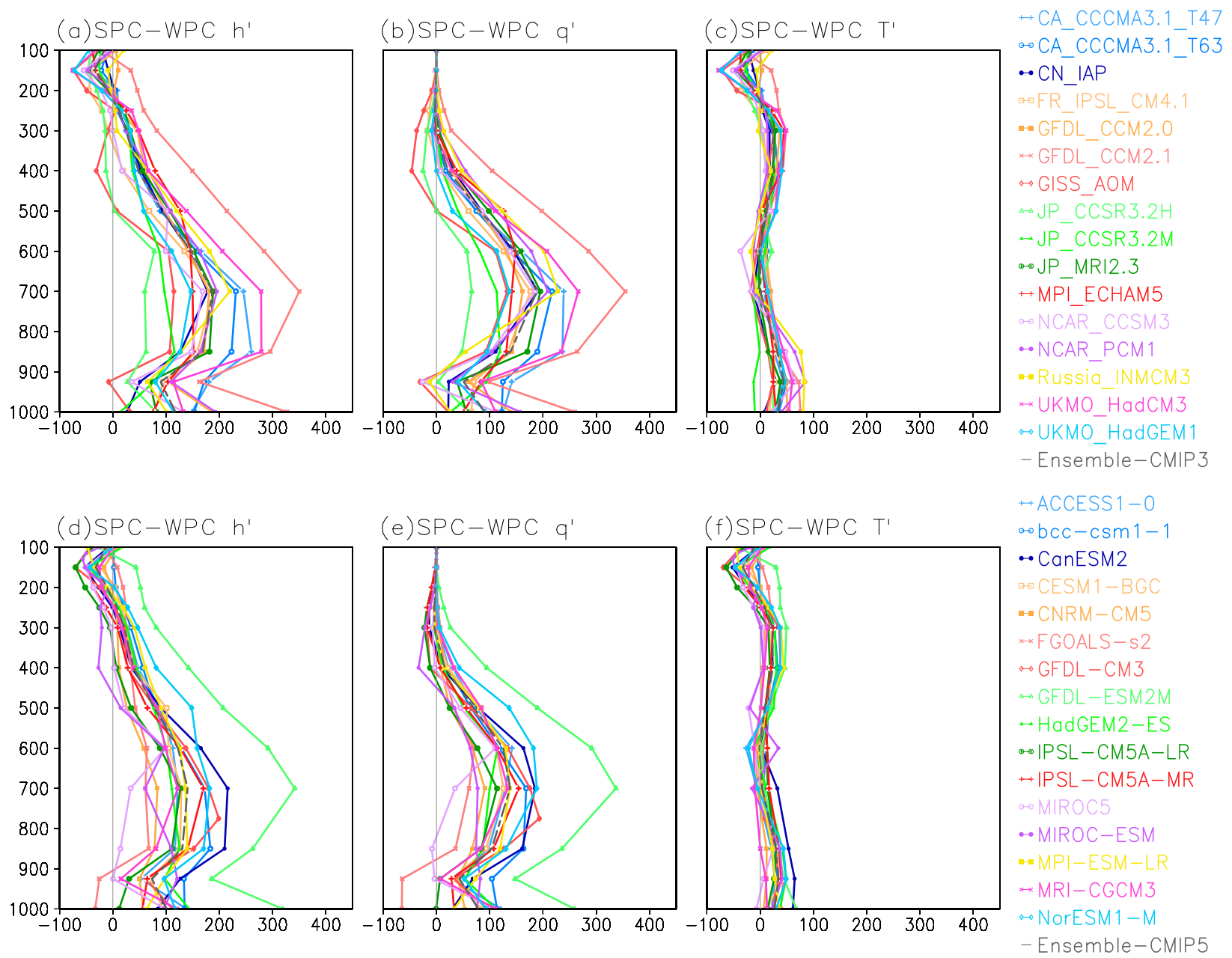

FIG. 9. Differences in changes (i.e., SPC minus WPC) of vertical profiles between the SPC and WPC areas. (top) Shown are the (a) $h^{\prime}$, (b) $q^{\prime}$, and (c) $T^{\prime}$ from the CMIP3 model simulations $\left(\mathrm{J} \mathrm{kg}^{-1}\right)$. (bottom) As in (top), but from the CMIP5 model simulations. The gray dashed line denotes the ensemble mean.

To highlight the above arguments, Fig. 8 b shows the respective contribution of the increased MSE and the mean vertical structure of vertical velocity to the $-M_{h}^{\prime}$ between the SPC and WPC areas. The positive difference in $-M_{h}^{\prime}$ between the SPC and WPC areas shows an ensemble mean of $0.003 \mathrm{~J} \mathrm{~kg}^{-1} \mathrm{~Pa}^{-1}$ and one SD between 0.0025 and $0.005 \mathrm{~J} \mathrm{~kg}^{-1} \mathrm{~Pa}^{-1}$. The results indicate a greater $-M_{h}^{\prime}$ value in the SPC than in the WPC areas for all models, as shown in Fig. 7b. Decomposing $-M_{h}^{\prime}$ (Fig. 8b) shows further that the difference in $-M_{h}^{\prime}$ is equally caused by the difference of the mean vertical structure of vertical velocity (i.e., $\Omega_{\mathrm{SPC}}-\Omega_{\mathrm{WPC}}$ ) and the increased MSE (i.e., $\left.\partial_{p} h_{\mathrm{SPC}}^{\prime}-\partial_{p} h_{\mathrm{WPC}}^{\prime}\right)$, with a similar averaged value of $0.002 \mathrm{~J} \mathrm{~kg}^{-1} \mathrm{~Pa}^{-1}$. The former implies a more bottomheavy structure of vertical velocity in the SPC than in the WPC areas. The detailed impact of the bottom-heavy structure will be discussed in the next section. The latter implies that the troposphere in the SPC area is warmer or moister (or both) than that in the WPC area.

Further examining changes in MSE between the SPC and WPC areas shows that the difference of MSE between the SPC and WPC areas is mainly caused by changes in water vapor (Fig. 9). The MSE has a maximum ranging between 100 and $300 \mathrm{~J} \mathrm{~kg}^{-1}$ in the lower troposphere around $700 \mathrm{hPa}$. This is mainly contributed by additional water vapor in the SPC areas (Figs. 9b,e). The contributions due to changes in temperature are relatively small, which are typically less than $100 \mathrm{~J} \mathrm{~kg}^{-1}$ among all 32 GCMs simulations (Figs. 9c,f). The increased water vapor associated with the original warming that is induced by increased $\mathrm{CO}_{2}$ should not be too different between the SPC and WPC areas. One possibility causing the water vapor difference may be related to the different vertical structure of the vertical velocity between these two areas. In the SPC areas, the vertical 
velocity structure is more bottom heavy, which implies a stronger partition of shallow convection. The stronger or more frequent shallow convection can transport more water vapor into the low troposphere from the PBL, leading to a significant increase of water vapor at the low troposphere and a more unstable atmosphere. Estimating the vertical advection related to the different vertical structures between the SPC and WPC areas (figure not shown) presents structures compatible with Figs. 9b,e. The strengthening of circulation also contributes more increased water vapor in the low troposphere but with a smaller magnitude compared with that from the vertical structure changes. In other words, the main cause for the difference of $-M_{h}^{\prime}$ is dominated by the difference of the mean vertical structure of vertical velocity, which is related to the different partition of shallow and deep convection in the SPC and WPC areas. It also implies that shallow convection may strengthen regional circulation under global warming.

\section{The role of shallow convection}

The mean vertical profile of convection usually results from a combination of different types of convection. In this study, we focus on two dominant types-namely, deep and shallow convection (Back and Bretherton 2009). When deep convection dominates, such as what usually happens in the western Pacific warm pool, the vertical profile of vertical velocity tends to be more top heavy. When shallow convection dominates, such as what generally occurs in the eastern Pacific ITCZ, the vertical profile of vertical velocity becomes more bottom heavy (Back and Bretherton 2006). To understand more about the role of deep and shallow convection associated, respectively, with top- and bottom-heavy structures in tropical circulations, we assume that the shape of vertical velocity $\Omega$ can be decomposed into contributions from shallow and deep convection:

$$
\Omega=\alpha \Omega_{1}+\beta \Omega_{2} .
$$

Here, $\Omega_{1}$ stands for a typical profile for deep convection, such as those shown in previous studies (e.g., Yanai et al. 1973; Back and Bretherton 2009). The $\Omega_{2}$ denotes a profile for shallow convection, whose magnitude is concentrated in the lower troposphere (e.g., Kodama et al. 2009; Takayabu et al. 2010). In (12), $\alpha$ and $\beta$ are the partition coefficients of deep and shallow convection, respectively, with a constraint $\alpha+\beta=1$ while assuming that $\alpha$ and $\beta$ will not significantly change under global warming. The change in gross moist stability due to increased $h$ can then be expressed as a result of changes in deep and shallow convection, separately:

$$
M_{h}^{\prime}=\alpha M_{h_{1}}^{\prime}+\beta M_{h_{2}}^{\prime} .
$$

Previous studies (Back and Bretherton 2006) indicated that deep convection leads to a positive contribution, while shallow convection induces a negative contribution when considering the climatology of the convection profile. This implies that deep convection tends to export MSE out of the atmospheric column, which tends to stabilize the atmosphere. In contrast, shallow convection imports MSE into the atmospheric column, which tends to destabilize the atmosphere. In an anomalous field induced by global warming, since the effect associated with increased water vapor dominates, both $M_{h_{1}}^{\prime}$ and $M_{h_{2}}^{\prime}$ tend to be negative, but $\left|M_{h_{2}}^{\prime}\right|>\left|M_{h_{1}}^{\prime}\right|$ because of the strong cancellation between the lower- and uppertropospheric contributions in deep convection (Yu et al. 1998). One should also note that shallow convection does not have an upper-tropospheric contribution. In other words, the final value of $M_{h_{1}}^{\prime}$ will depend more on the partition between $\alpha$ and $\beta$ when $h^{\prime}$ is positive, and vice versa. If $\alpha$ is greater (i.e., a top-heavy profile dominates), $M_{h}^{\prime}$ is greater (i.e., smaller negative). If $\beta$ is larger (i.e., a bottom-heavy profile dominates), $M_{h}^{\prime}$ becomes smaller (i.e., more negative). This implies that the top-heavy profile of vertical velocity tends to induce a less strengthened tropical circulation (owing to smaller negative $M_{h}^{\prime}$ ), while the bottom-heavy profile of vertical velocity tends to induce a more strengthened tropical circulation (owing to greater negative $M_{h}^{\prime}$ ) under global warming (Fig. 8). Figures 2a,b and 5 show more bottomheavy profiles in the SPC than in the WPC areas (i.e., $\beta_{\mathrm{SPC}}>\beta_{\mathrm{WPC}}$ and $\left.\alpha_{\mathrm{SPC}}<\alpha_{\mathrm{WPC}}\right)$. From the stability perspective, $M_{\Omega}^{\prime}>0$ because of the effect of deepened convection, which tends to reduce tropical circulation in both areas (Fig. 8). In short, the different partition of deep and shallow convection results in the combined effect of increased MSE and the change in the vertical profile of convection, which further stabilizes (destabilizes) the tropical atmosphere and benefits the weakened (strengthened) circulation in the WPC (SPC) areas in a warmer climate.

\section{Conclusions and discussion}

In this study, we started with developing an understanding of why the vertical velocity from convection can be either enhanced or reduced when the resulting precipitation increases because of global warming. In this process, we ended up finding a possible impact of shallow convection on deep convection areas and their corresponding precipitation amounts. This also provides a linkage for projecting and understanding future circulation change from the current climate. As discussed in 
previous studies (e.g., Back and Bretherton 2006, 2009; C. Zhang and C. Chou 2013, personal communication), on one hand, shallow convection transports energy and moisture from the PBL into the free atmosphere and enhances deep convection and the corresponding precipitation. On the other hand, the shallow circulation associated with shallow convection tends to import MSE, which destabilizes the atmosphere, and then enhances deep convection. In other words, shallow convection can enhance tropical precipitation if it coexists with deep convection.

As the earth becomes warmer, what is the role of shallow convection? The strong spatial variation of precipitation provides a good basis for answering the above question without getting into the detailed process of shallow convection. Since the spatial distribution of precipitation changes is mainly caused by atmospheric dynamics, the distribution changes can also be used to study mechanisms of the dynamic contribution (i. e., the change in tropical circulation). In this regard, we examined multimodel datasets of CMIP3 and CMIP5 by considering the MSE budget in convective regions with positive precipitation anomalies, where the corresponding vertical velocity can be either strengthened (SPC) or weakened (WPC). The result is summarized in the schematic diagram (Fig. 10).

\section{a. MSE budget}

In an anomalous MSE budget [e.g., (3)], the term $\left\langle\omega^{\prime} \partial_{p} \bar{h}\right\rangle$ is commonly used to represent changes in vertical velocity. From the budget analysis in this study, a positive $-\left\langle\bar{\omega} \partial_{p} h^{\prime}\right\rangle$ and $F^{\text {net }}$ are the main contributors to the increased moist static energy associated with the anomalous vertical velocity in both the SPC and WPC areas. Comparing the difference in MSE budget between these two areas, a consistently positive value is seen in both areas with strengthened and weakened anomalous circulation. In the SPC area, the larger energy transportation related to the anomalous vertical velocity is partly contributed by the additional $-\langle\mathbf{v} \cdot \nabla(T+q)\rangle^{\prime}$ and $F^{\text {net }^{\prime}}$, which are mainly due to the increase of horizontal temperature advection and less emission of longwave radiation flux related to the anomalous convection in this area. From the boundary condition perspective, the change in the SST pattern may also play a role. It shows a larger (smaller) warmer anomaly in the strengthened (weakened) area, illustrating a tendency found in previous studies (e.g., Ma et al. 2012; Ma and Xie 2013), however the magnitude differences between the strengthened and weakened areas are smaller in this study. We note that the remote influence of change in SST was not considered here.
However, in spite of these differences between the SPC and WPC areas, the changes in vertical transport of MSE related to the opposite anomalous circulation (i.e., $\left.\left\langle\omega^{\prime} \partial_{p} \bar{h}\right\rangle\right)$ do not show the correspondingly expected opposite result (Fig. 10a). In other words, the diverse response of circulation change cannot be directly explained and distinguished through $\left\langle\omega^{\prime} \partial_{p} \bar{h}\right\rangle$ or as well as the MSE budget in this study. Changes in the vertical structure of vertical velocity in our study areas are complicated and not vertically consistent, especially in the WPC area. Therefore, the integrated $\left\langle\omega^{\prime} \partial_{p} \bar{h}\right\rangle$ over complicated vertical profiles (Fig. 10a) is positive over both the SPC and WPC areas, even though the changes of vertical velocity are almost opposite (Fig. 10a). We note that the vertical advection associated with increased MSE $-\left\langle\bar{\omega} \partial_{p} h^{\prime}\right\rangle$, which is related to changes in atmospheric stability (Chou and Chen 2010; Chou et al. 2013), reveals a consistently positive tendency in both areas. The quantity $-\left\langle\bar{\omega} \partial_{p} h^{\prime}\right\rangle$ integrates the information about whether atmospheric conditions and vertical structure favor the strengthening or weakening of convection. In addition, the quantity also combines the effect of the strength and vertical profile of mean vertical velocity $\bar{\omega}$ (Fig. 10b). Therefore, from a qualitative point of view, we further clarified and discussed the impact of vertical structure of vertical velocity on the results associated with change in circulation and the relevant atmospheric stability. Utilizing the decomposition of vertical velocity, the simplified MSE budget can then be expressed as a quantity related to the gross moist stability. The gross moist stability, a representation of the effective static stability including the moisture effect, describes the energy required for per-unit upward motion in deep convection. This can help us examine mechanisms that are associated with changes in vertical velocity and the corresponding tropical circulation.

\section{b. Vertical structure and change in gross moist stability}

In the SPC area, the bottom-heavy structure of mean vertical velocity tends to result in a more negative gross moist stability (Fig. 10c) by importing more MSE into the atmospheric column, which encourages the atmosphere to become more unstable. This is favorable for the further enhancement of convection and the corresponding tropical circulation. In the WPC area, on the other hand, the top-heavy profile of mean vertical velocity results in less negative gross moist stability (Fig. 10c), which implies that the atmosphere is less unstable. Combined with the effect of convection deepening, this tends to reduce convection and the corresponding tropical circulation. Thus, the mean vertical profile of vertical velocity becomes an important 

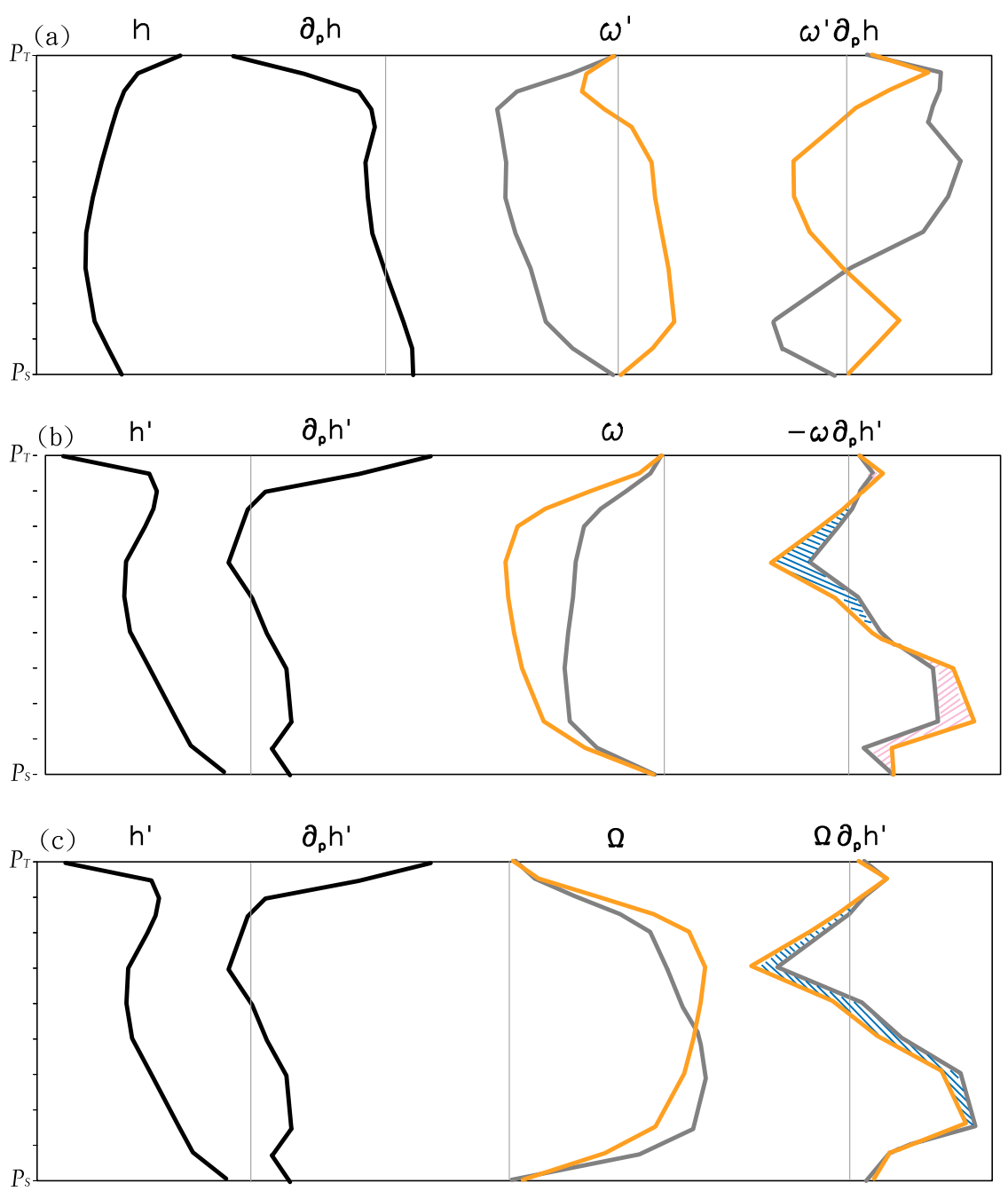

FIG. 10. A schematic diagram summarizing the vertical profiles associated with changes in the vertical velocity in the SPC and WPC areas. The variables for each profile are written at the top of each panel. The black curve is the profile for both areas and the gray (orange) curve is the profile in the SPC (WPC) area. The striped areas in (b) and (c) represent the difference between the SPC and WPC areas (i.e., SPC - WPC). The blue (pink) striped areas mean positive (negative) differences.

factor in determining changes in regional gross moist stability and further affects circulation in a warmer climate. A bottom-heavy profile is related to a greater partition of shallow convection, while a top-heavy profile implies the dominance of deep convection in the area (Back and Bretherton 2006). In this study, therefore, a hypothesis is suggested: the partition of shallow convection in tropical convection becomes a considerable factor. Shallow convection tends to enhance deep convection via importing more MSE. It can also transport more moisture upward and then enhance deep convection (Fig. 9) in a warmer climate.

In this study, we also found that the deepening of tropical convection is a common feature in convective regions under global warming (i.e., the negative $-M_{\Omega}^{\prime}$; Chou et al. 2013). This tends to increase atmospheric stability by exporting more MSE, which then weakens the tropical circulation (Chou and Chen 2010). The richget-richer mechanism (Chou and Neelin 2004; Chou et al. 2009) associated with the increased water vapor is also commonly found in tropical convective regions (i.e., the positive $-M_{h}^{\prime}$ )

\section{c. Final remarks}

The role of shallow convection has been proposed to account for the maintenance of climate variability on various time scales (e.g., Jiang et al. 2015; Inoue and Back 2015a). In this study, the impact of shallow 
convection on circulation under global warming is illustrated for the first time through a decomposition of gross moist stability related to convective energy transport. In a warmer and more humid climate, the climatological vertical structures associated with deep and shallow convection play different roles in adjusting atmospheric stability, energy transport, and large-scale circulation, which further benefit the atmospheric circulation toward opposite changes, even within convective areas with increased precipitation. The bottom-heavy structure favors deep convection and strengthening of tropical circulation, while a top-heavy structure tends to suppress deep convection and weaken tropical circulation. The shallow convection may be a considerable factor in regional changes of tropical circulation.

Shallow convection is associated with the development of deep convection and the tropical circulation and has been said to be associated with the development of other atmospheric phenomena such as the MJO (e.g., Jiang et al. 2015; Chang et al. 2015) in many studies. We note that there is more than one process that can lead to the weakening or strengthening of the ascending motion, and the mean vertical profile of convection is usually a result of the net effect of different convection types. In this study, the influence of the vertical structure associated with shallow and deep convection on circulation change was discussed from a conceptual partition assumption. To more precisely examine the hypothesis and contribution of bottom- and top-heavy structure on the change in stability in a warmer climate and clarify its potential impact on circulation change combined with other mechanisms-for example, the SST pattern change associated with enhanced equatorial warming, especially the equatorial Pacific (e.g., Ma and Xie 2013; Chadwick et al. 2013; He et al. 2014)_further studies are required.

Acknowledgments. We acknowledge the two anonymous reviewers' many constructive comments for improving the quality of this paper. We also thank Dr. Min-Hui Lo, Dr. Huang-Hsiung Hsu, and Dr. Jui-Lin (Frank) Li for providing valuable suggestions for the revision. We thank the modeling groups, the Program for Climate Model Diagnosis and Intercomparison (PCMDI) and the WCRP's Working Group on Coupled Modelling (WGCM), for collecting and archiving the WCRP CMIP3 and CMIP5 multimodel datasets for analysis. We thank the climate modeling groups (listed in Tables 1 and 2 of this paper) for producing and making available their model outputs. The CMIP data archived at the Lawrence Livermore National Laboratory are supported by the Office of Science, U.S. Department of Energy. This work was supported jointly by the Academia Sinica and the
Ministry of Science and Technology (MOST) of Taiwan under MOST-102-2111-M-001-002-MY3 and MOST103-2111-M-008-026-MY2.

\section{REFERENCES}

Adler, R. F., G. Gu, J.-J. Wang, G. J. Huffman, S. Curtis, and D. Bolvin, 2008: Relationships between global precipitation and surface temperature on interannual and longer timescales (1979-2006). J. Geophys. Res., 113, D22104, doi:10.1029/ 2008JD010536.

Allan, R. P., and B. J. Soden, 2007: Large discrepancy between observed and simulated precipitation trends in the ascending and descending branches of the tropical circulation. Geophys. Res. Lett., 34, L18705, doi:10.1029/2007GL031460.

,,-- V. O. John, W. Ingram, and P. Good, 2010: Current changes in tropical precipitation. Environ. Res. Lett., 5, 025205, doi:10.1088/1748-9326/5/2/025205.

Allen, M. R., and W. J. Ingram, 2002: Constraints on future changes in climate and the hydrologic cycle. Nature, 419, 224-232, doi:10.1038/nature01092.

Anderson, B. T., B. R. Lintner, B. Langenbruner, J. D. Neelin, E. Hawkins, and J. Sykus, 2015: Sensitivity of terrestrial precipitation to the structural evolution of sea surface temperatures. Geophys. Res. Lett., 42, 1190-1196, doi:10.1002/ 2014 GL062593.

Back, L. E., and C. S. Bretherton, 2006: Geographic variability in the export of moist static energy and vertical motion profiles in the tropical Pacific. Geophys. Res. Lett., 33, L17810, doi:10.1029/ $2006 \mathrm{GL} 026672$.

_— and _-, 2009: A simple model of climatological rainfall and vertical motion patterns over the tropical oceans. J. Climate, 22, 6477-6497, doi:10.1175/2009JCLI2393.1.

Bony, S., G. Bellon, D. Klocke, S. Sherwood, S. Fermepin, and S. Denvil, 2013: Robust direct effect of carbon dioxide on tropical circulation and regional precipitation. Nat. Geosci., 6 , 447-451, doi:10.1038/ngeo1799.

Chadwick, R., I. Boutle, and G. Martin, 2013: Spatial patterns of precipitation change in CMIP5: Why the rich do not get richer in the tropics. J. Climate, 26, 3803-3822, doi:10.1175/ JCLI-D-12-00543.1.

Chang, C.-W. J., W.-L. Tseng, H.-H. Hsu, N. Keenlyside, and B.-J. Tsuang, 2015: The Madden-Julian oscillation in a warmer world. Geophys. Res. Lett., 42, 6034-6042, doi:10.1002/ 2015GL065095.

Chen, C. A., C. Chou, and C. T. Chen, 2012: Regional perspective on mechanisms for tropical precipitation frequency and intensity under global warming. J. Climate, 25, 8487-8501, doi:10.1175/JCLI-D-12-00096.1.

Chou, C., and J. D. Neelin, 2004: Mechanisms of global warming impacts on regional tropical precipitation. J. Climate, 17, 2688-2701, doi:10.1175/1520-0442(2004)017<2688: MOGWIO $>2.0 . \mathrm{CO} ; 2$.

- and C.-A. Chen, 2010: Depth of convection and the weakening of tropical circulation in global warming. J. Climate, 23, 3019-3030, doi:10.1175/2010JCLI3383.1.

- , and C.-W. Lan, 2012: Changes in the annual range of precipitation under global warming. J. Climate, 25, 222-235, doi:10.1175/JCLI-D-11-00097.1.

_ J.-Y. Tu, and P.-H. Tan, 2007: Asymmetry of tropical precipitation change under global warming. Geophys. Res. Lett., 34, L17708, doi:10.1029/2007GL030327. 
_ J. D. Neelin, C.-A. Chen, and J.-Y. Tu, 2009: Evaluating the "rich-get-richer" mechanism in tropical precipitation change under global warming. J. Climate, 22, 1982-2005, doi:10.1175/ 2008JCLI2471.1.

—, C.-A. Chen, P.-H. Tan, and K.-T. Chen, 2012: Mechanisms for global warming impacts on precipitation frequency and intensity. J. Climate, 25, 3291-3306, doi:10.1175/ JCLI-D-11-00239.1.

- , T.-C. Wu, and P.-H. Tan, 2013: Changes in gross moist stability in the tropics under global warming. Climate Dyn., $\mathbf{4 1}$, 2481-2496, doi:10.1007/s00382-013-1703-2.

Collins, M., and Coauthors, 2013: Long-term climate change: Projections, commitments and irreversibility. Climate Change 2013: The Physical Science Basis, T. F. Stocker et al., Eds., Cambridge University Press, 1029-1136.

Cubasch, U., and Coauthors, 2001: Projections of future climate change. Climate Change 2001: The Scientific Basis, J. T. Houghton et al., Eds., Cambridge University Press, 525-582.

Emori, S., and S. J. Brown, 2005: Dynamic and thermodynamic changes in mean and extreme precipitation under changed climate. Geophys. Res. Lett., 32, L17706, doi:10.1029/ 2005 GL023272.

Gu, G., R. F. Adler, G. J. Huffman, and S. Curtis, 2007: Tropical rainfall variability on interannual-to-interdecadal and longer time scales derived from the GPCP monthly product. J. Climate, 20, 4033-4046, doi:10.1175/JCLI4227.1.

He, J., B. J. Soden, and B. Kirtman, 2014: The robustness of the atmospheric circulation and precipitation response to future anthropogenic surface warming. Geophys. Res. Lett., 41, 2614 2622, doi:10.1002/2014GL059435.

Held, I. M., and B. J. Soden, 2006: Robust responses of the hydrological cycle to global warming. J. Climate, 19, 5686-5699, doi:10.1175/JCLI3990.1.

Holloway, C. E., and J. D. Neelin, 2009: Moisture vertical structure, column water vapor, and tropical deep convection. J. Atmos. Sci., 66, 1665-1683, doi:10.1175/2008JAS2806.1.

Inoue, K., and L. Back, 2015a: Column-integrated moist static energy budget analysis on various time scales during TOGA COARE. J. Atmos. Sci., 72, 1856-1871, doi:10.1175/ JAS-D-14-0249.1.

__ and _ _ 2015b: Gross moist stability assessment during TOGA COARE: Various interpretations of gross moist stability. J. Atmos. Sci., 72, 4148-4166, doi:10.1175/ JAS-D-15-0092.1.

Jiang, X., and Coauthors, 2015: Vertical structure and physical processes of the Madden- Julian oscillation: Exploring key model physics in climate simulations. J. Geophys. Res. Atmos., 120, 4718-4748, doi:10.1002/2014JD022375.

Knutson, T. R., and S. Manabe, 1995: Time-mean response over the tropical Pacific to increased $\mathrm{CO}_{2}$ in a coupled oceanatmosphere model. J. Climate, 8, 2181-2199, doi:10.1175/ 1520-0442(1995)008<2181:TMROTT>2.0.CO;2.

Kodama, Y.-M., M. Katsumata, S. Mori, S. Satoh, Y. Hirose, and H. Ueda, 2009: Climatology of warm rain and associated latent heating derived from TRMM PR observations. J. Climate, 22, 4908-4929, doi:10.1175/2009JCLI2575.1.

Kumar, A., F. Yang, L. Goddard, and S. Schubert, 2004: Differing trends in the tropical surface temperatures and precipitation over land and oceans. J. Climate, 17, 653-664, doi:10.1175/ 1520-0442(2004)017<0653:DTITTS>2.0.CO;2.

Liepert, B. G., and M. Previdi, 2009: Do models and observations disagree on the rainfall response to global warming? J. Climate, 22, 3156-3166, doi:10.1175/2008JCLI2472.1.
Liu, C., and R. P. Allan, 2012: Multisatellite observed responses of precipitation and its extremes to interannual climate variability. J. Geophys. Res., 117, D03101, doi:10.1029/2011JD016568.

Liu, S. C., C. Fu, C.-J. Shiu, J.-P. Chen, and F. Wu, 2009: Temperature dependence of global precipitation extremes. Geophys. Res. Lett., 36, L17702, doi:10.1029/2009GL040218.

Luo, J. J., W. Sasaki, and Y. Masumoto, 2012: Indian Ocean warming modulates Pacific climate change. Proc. Natl. Acad. Sci. USA, 109, 18 701-18 706, doi:10.1073/pnas.1210239109.

Ma, J., and S.-P. Xie, 2013: Regional patterns of sea surface temperature change: A source of uncertainty in future projections of precipitation and atmospheric circulation. J. Climate, 26, 2482-2501, doi:10.1175/JCLI-D-12-00283.1.

- _ - and Y. Kosaka, 2012: Mechanisms for tropical tropospheric circulation change in response to global warming. J. Climate, 25, 2979-2994, doi:10.1175/JCLI-D-11-00048.1.

Meehl, G. A., C. Covey, K. E. Taylor, T. Delworth, R. J. Stouffer, M. Latif, B. McAvaney, and J. F. B. Mitchell, 2007a: The WCRP CMIP3 multimodel dataset: A new era in climate change research. Bull. Amer. Meteor. Soc., 88, 1383-1394, doi:10.1175/BAMS-88-9-1383

— Change 2007: The Physical Science Basis, S. Solomon et al., Eds., Cambridge University Press, 747-845.

Neelin, J. D., 2007: Moist dynamics of tropical convection zones in monsoons, teleconnections, and global warming. The Global Circulation of the Atmosphere, T. Schneider and A. H. Sobel, Eds., Princeton University Press, 267-301.

— , and J.-Y. Yu, 1994: Modes of tropical variability under convective adjustment and the Madden-Julian oscillation. Part I: Analytical theory. J. Atmos. Sci., 51, 1876-1894, doi:10.1175/ 1520-0469(1994)051<1876:MOTVUC >2.0.CO;2.

— model-formulation. J. Atmos. Sci., 57, 1741-1766, doi:10.1175/ 1520-0469(2000)057<1741:AQETCM > 2.0.CO;2.

— M. Münnich, H. Su, J. E. Meyerson, and C. E. Holloway, 2006: Tropical drying trends in global warming models and observations. Proc. Natl. Acad. Sci. USA, 103, 6110-6115, doi:10.1073/pnas.0601798103.

O'Gorman, P. A., and T. Schneider, 2009: The physical basis for increases in precipitation extremes in simulations of 21stcentury climate change. Proc. Natl. Acad. Sci. USA, 106, 14 773-14 777, doi:10.1073/pnas.0907610106.

Seager, R., N. Naik, and G. A. Vecchi, 2010: Thermodynamic and dynamic mechanisms for large-scale changes in the hydrological cycle in response to global warming. J. Climate, 23, 4651-4668, doi:10.1175/2010JCLI3655.1.

Shi, L., and J. J. Bates, 2011: Three decades of intersatellitecalibrated High-Resolution Infrared Radiation Sounder upper tropospheric water vapor. J. Geophys. Res., 116, D04108, doi:10.1029/2010JD014847.

Sobel, A. H., and J. D. Neelin, 2006: The boundary layer contribution to intertropical convergence zones in the quasi-equilibrium tropical circulation model framework. Theor. Comput. Fluid Dyn., 20, 323-350, doi:10.1007/s00162-006-0033-y.

Sohn, B. J., and S.-C. Park, 2010: Strengthened tropical circulations in past three decades inferred from water vapor transport. J. Geophys. Res., 115, D15112, doi:10.1029/2009JD013713.

Stott, P. A., and J. A. Kettleborough, 2002: Origins and estimates of uncertainty in predictions of twenty-first century temperature rise. Nature, 416, 723-726, doi:10.1038/416723a.

Sun, Y., S. Solomon, A. Dai, and R. W. Portmann, 2007: How often will it rain? J. Climate, 20, 4801-4818, doi:10.1175/JCLI4263.1. 
Takayabu, Y. N., S. Shige, W.-K. Tao, and N. Hirota, 2010: Shallow and deep latent heating modes over tropical oceans observed with TRMM PR spectral latent heating data. J. Climate, 23, 2030-2046, doi:10.1175/2009JCLI3110.1.

Taylor, K. E., R. J. Stouffer, and G. A. Meehl, 2012: An overview of CMIP5 and the experiment design. Bull. Amer. Meteor. Soc., 93, 485-498, doi:10.1175/BAMS-D-11-00094.1.

Tokinaga, H., S.-P. Xie, A. Timmermann, S. McGregor, T. Ogata, H. Kubota, and Y. M. Okumura, 2012: Regional patterns of tropical Indo-Pacific climate change: Evidence of the Walker circulation weakening. J. Climate, 25, 1689-1710, doi:10.1175/ JCLI-D-11-00263.1.

Trenberth, K. E., and Coauthors, 2007: Observations: Surface and atmospheric climate. Climate Change 2007: The Physical Science Basis, S. Solomon et al., Eds., Cambridge University Press, 235336.

Vecchi, G. A., and B. J. Soden, 2007: Global warming and the weakening of the tropical circulation. J. Climate, 20, 43164340, doi:10.1175/JCLI4258.1.

, - A. T. Wittenberg, I. M. Held, A. Leetmaa, and M. J. Harrison, 2006: Weakening of tropical Pacific atmospheric circulation due to anthropogenic forcing. Nature, 441, 73-76, doi:10.1038/nature04744.

Wentz, F. J., L. Ricciardulli, K. Hilburn, and C. Mears, 2007: How much more rain will global warming bring? Science, 317, 233235, doi:10.1126/science.1140746.

Yanai, M., S. Esbensen, and J.-H. Chu, 1973: Determination of bulk properties of tropical cloud clusters from large-scale heat and moisture budgets. J. Atmos. Sci., 30, 611-627, doi:10.1175/ 1520-0469(1973)030<0611:DOBPOT >2.0.CO;2.

Yu, J.-Y., and J. D. Neelin, 1997: Analytic approximations for moist convectively adjusted regions. J. Atmos. Sci., 54, 1054-1063, doi:10.1175/1520-0469(1997)054<1054:AAFMCA > 2.0.CO;2.

C. Chou, and J. D. Neelin, 1998: Estimating the gross moist stability of the tropical atmosphere. J. Atmos. Sci. 55, 1354-1372, doi:10.1175/1520-0469(1998)055<1354: ETGMSO $>2.0 . \mathrm{CO} ; 2$.

Zhang, X., F. W. Zwiers, G. C. Hegerl, F. H. Lambert, N. P. Gillett, S. Solomon, P. A. Stott, and T. Nozawa, 2007: Detection of human influence on twentieth-century precipitation trends. Nature, 448, 461-465, doi:10.1038/ nature 06025 . 